\title{
Placer, salud y sociabilidad. El hecho alimentario a través del jamón ibérico*
}

\author{
Pleasure, Health and Sociability. \\ Food Fact and Food Choice through Iberian Ham
}

\author{
Santiago Amaya-Corchuelo ${ }^{1}$ \\ Universidad de Cádiz \\ Mario Fernández Zarza ${ }^{2}$ \\ Universidad de Sevilla \\ Encarnación Aguilar Criado ${ }^{3}$ \\ Universidad de Sevilla
}

\section{RESUMEN}

A medida que avanzan los estudios sobre el polisémico ámbito de la alimentación humana, resulta más necesario considerar mayor número de variables para analizar con solvencia el hecho alimentario. Más allá de los estudios sobre las fases de producción y distribución, nuestra propuesta se centra en la fase del consumo y trata de identificar los elementos que explican por qué las sociedades seleccionan y prefieren unos alimentos en detrimento de otros. Actualmente, la selección alimentaria está intrínsecamente presente en el hecho alimentario de las sociedades modernas, relegando a un segundo plano los factores biológicos y fisiológicos, en relación a parámetros dominantes comparados con el placer, la salud y la sociabilidad. Mediante una combinación de técnicas cuantitativas y cualitativas, este estudio propone la relevancia de dimensiones como el placer y la salud como elementos que guían a los consumidores para elegir un determinado producto gourmet, como es el caso del jamón ibérico en España.

Palabras clave: Selección de alimentos; Hecho alimentario; Placer; Salud; Sociabilidad; Jamón ibérico.

\section{SUMMARY}

As studies on the polysemic field of human nutrition progress, it is has become necessary to consider a greater number of variables when analysing the reality of food. Our proposal goes beyond studies based on the production and distribution phases, and focuses instead on the consumption phase in an effort to identify the elements that explain why societies choose and pre-

\footnotetext{
* Esta investigación es el resultado del proyecto I+D (CSO2013-42468-P) del Ministerio de Economía y Competitividad Las marcas de calidad en el mundo rural: nuevos retos para productores y consumidores.

${ }^{1}$ Correo electrónico: santiago.amaya@uca.es. ORCID iD: <https://orcid.org/0000-0001-6633-3842>.

${ }^{2}$ Correo electrónico: mfzarza@us.es. ORCID iD: <http://orcid.org/0000-0002-4919-2571>.

3 Correo electrónico: eaguilar@us.es. ORCID iD: <https://orcid.org/0000-0003-0212-8377>.
} 
fer some foods over others. Nowadays, food choice is intrinsically present in food as a reality of modern societies, relegating biological and physiological factors in relation to the dominant parameters of pleasure, health and sociability. Through a combination of quantitative and qualitative techniques, this study proposes pleasure and health as elements that guide consumers to choosing a particular gourmet product, as in the case of Iberian ham in Spain.

Keywords: Food Choice; Food Fact; Pleasure; Health; Sociability; Iberian Ham.

\section{INTRODUCCIÓN}

Las investigaciones sobre valores culturales y sociales de la alimentación forman parte inherente de varias disciplinas, abordando entre otras, reflexiones en torno al estatus individual/social de la comida (Aguilar Piña 2014). Si nos centramos en las últimas décadas, la relación entre alimentación y cultura se sustancia fundamentalmente en varios campos. Por un lado, la importancia de la alimentación en el debate global/local (Bauman 2010) y derivaciones de este gran campo en torno a la patrimonialización de la comida versus modernización (Ascher 2005), migraciones y turismo o comida vinculada al ciberespacio y redes. Por otro, la gran preocupación en torno a la carencia alimentaria, acompañada de propuestas que abordan de forma aplicada la seguridad alimentaria (Díaz y Gómez 2005). Finalmente se sigue prestando atención a aspectos con una larga trayectoria reflexiva desde las ciencias sociales como son los valores de la alimentación con la intención de conocer a las sociedades actuales. Es una fórmula para traducir el mundo mediante los símbolos culinarios de sus fiestas, de los espacios para el consumo y la sociabilidad, de las distinciones de género o de clase, del comportamiento de los consumidores y sus dispares hábitos alimentarios (Douglas e Isherwood 1979; Goody 1995; Espeitx 2005).

Una idea clave de todo ello, es que el hombre, que es un animal omnívoro, no está solo guiado por su fisiología en las prácticas relacionadas con las selecciones alimentarias que efectúa en el medio, de forma que estas acciones están fuertemente sometidas a sus valores culturales (Lévi Strauss 2004 [1965]; De Garine 1998; Contreras 2002; Gracia 2010). La elección de los alimentos en nuestras sociedades es una decisión motivada por multitud de factores, lo cual puede presentarse ante nuestros ojos como un asunto arduo para ser investigado. Uno de los precedentes en el estudio de la alimentación lo desarrolló la escuela del estructuralismo, cuando tras la segunda guerra mundial, Levi Strauss (1965: 19-29), identificó la comida como un campo fundamental de investigación mediante el que la cocina se convierte en lenguaje para expresar su estructura inconsciente.

Aquella fue una forma de dejar claro que el hecho alimentario implica prácticas, representaciones, imaginarios y clasificaciones que desvelan visiones diversas del mundo (López, Mariano y Medina 2017). Las culturas nunca dejan solos a los comensales a la hora de decidir sobre la comida; porque las normas y las gramáticas de la cocina, que vinculan texturas, sabores en platos y preparaciones, dan sentido social al comer. Definitivamente el debate acerca de qué es comer bien tiene que ver con la escala de valores de una cultura. Así en el ámbito alimentario de las sociedades complejas se están generando nuevos significados relacionados con el término gourmet, entendido como elección y consumo de alimentos de carácter secundario o no 
imprescindibles para la alimentación diaria y considerados más como placer y también como distintivo de clase (Solomon et al. 2006). Desde esta perspectiva los aspectos hedónicos destacan como los más valorados en la elección de los alimentos (Diez 1997; Solomon et al. 2006; Amaya-Corchuelo et al. 2016).

Por tanto, la alimentación puede abordarse tanto en el contexto de lo lúdico, placentero y hedónico como en el de lo saludable. Este hecho se encuentra particularmente relacionado con los sectores sociales más favorecidos económicamente, los cuales perciben la alimentación como una fuente de sensaciones y evocaciones sobre culturas y tradiciones locales. Este hecho constituye, particularmente en el ámbito europeo, una base sólida para el desarrollo rural a través de la valorización de las tradiciones culinarias. El discurso sobre estas tendencias es transversal y afecta a la economía, al desarrollo de los territorios, a las formas de acceso a los alimentos, a la producción y distribución agroalimentaria, al consumo, a la publicidad, al medioambiente, entre otras numerosas manifestaciones y representaciones culturales. Es esa transversalidad la que convierte al fenómeno del consumo de productos gourmet y de la tierra en un discurso político, intergeneracional y globalizado.

La frase ¡dime qué comes y te diré quién eres! nos lleva a relacionar la alimentación de cada pueblo (por sus ingredientes, origen, formas de transformación, etc.) con sus profundas raíces históricas. Este arraigo de los alimentos, sus funciones y sus significados, se van transformando y perdiendo gradualmente por la adopción de nuevos hábitos alimentarios o por la sustitución y la incorporación de otros. En este sentido, actualmente el papel de los consumidores es determinante, más aún cuando existe una tendencia que transforma las necesidades básicas de alimentación en gustos o deseos secundarios (Espeitx 2005; Leyva y Pérez 2015; Amaya-Corchuelo et al. 2016).

A ello hay que añadir que en cada estrato socioeconómico siguen operando diferencias entre alimentación cotidiana, comidas festivas y consumiciones fuera del hogar (Contreras y Gracia 2008). Esto a pesar de que, como señala De Garine (1998: 24), "hoy día, en los países modernos, es posible comer cualquier alimento, en cualquier momento, en cualquier sitio, en cualquier cantidad; si uno dispone de suficiente dinero". De esta manera cuando hablamos de consumidor y alimentación, por razones pragmáticamente financieras, la mayor parte de las investigaciones se concentran en el consumidor con poder adquisitivo. Son investigaciones costeadas por la industria agroalimentaria, donde se evalúan sus productos para mejorarlos ${ }^{4}$. Tales estudios son escasamente críticos en relación con el producto comercializado por dicha empresa. Pero más allá de determinismos económicos, en cada consumidor coexisten tendencias a demostrar su nivel económico con satisfacer su gula, disfrutar una dieta sana, su modernidad o su autenticidad cultural.

En el contexto alimentario español uno de los alimentos que mejor representa lo expresado es el jamón ibérico: un producto dotado de singulares características cua-

\footnotetext{
${ }^{4}$ En este sentido pueden verse a modo de ejemplo tantos artículos académicos: La certificación de la calidad y de la alimentación en jamones y paletas del cerdo ibérico (Silva, Reina y Ventanas 2010), o este otro trabajo de Jurado et al. (2007), Effect of ripenin time and rearing system on amino-acided related flavor compounds of Iberian ham. Como sobre todo el contenido de trabajos correspondientes a revistas del sector de la distribución alimentaria como Alimarket (<https:/ /www.alimarket.es/alimentacion/revista $>$ ), la revista Aral (<http://www.revistaaral.com/es/ revistas.php>) o la revista Distribución y consumo (<http://www.mercasa.es/publicaciones $>$ ).
} 
litativas (sabor, facilidad de preparación, textura de la carne, ausencia de aditivos químicos o sintéticos, identidad territorial, etc.) que hunde sus raíces en procesos tecnoeconómicos seculares correspondientes a los territorios y sociedades de dehesa ${ }^{5}$ (Campos 1984; Acosta, Díaz y Amaya 2001; Amaya-Corchuelo y Aguilar 2012). Así, el jamón ibérico (particularmente el de bellota) constituye un alimento socialmente elevado a la categoría de producto gourmet en los foros nacionales e internacionales. Por tanto, reúne algunas variables para ser percibido como marcador identitario, de clase social y como fuente hedónica, de placer, de salud y de sociabilidad. Podríamos decir que es un producto que cubre diferentes necesidades de los consumidores: psicológicas, de seguridad, de pertenencia social, de ego y de enriquecimiento de experiencias (Amaya-Corchuelo et al. 2016; Solomon et al. 2006).

En este punto pueden formularse ya algunas de las preguntas que vertebran este trabajo: ¿qué peso tienen las variables placer, salud y sociabilidad entre los consumidores españoles de jamón ibérico a la hora de adquirirlo?, ¿dominan estas variables sobre otras posibles?, ¿se elige este producto como fuente de prestigio social, o influyen más otras variables identitarias o de nutrición? Para desvelar estas interrogantes e hipótesis, aquí analizaremos fundamentalmente las percepciones ${ }^{6}$ de industriales y consumidores en torno a la salud, la sociabilidad y el placer derivados de la selección y del consumo de jamón ibérico.

\section{MARCO TEÓRICO CONCEPTUAL}

\section{A) Alimentarse COMO ACCión SELECTIVA Y HedóNICA}

Como señalamos antes, la alimentación humana se orienta por múltiples variables. Desde nuestra perspectiva el hecho de la elección de alimentos constituye una cuestión central a la hora de analizar el contexto de la alimentación de cada grupo humano. En relación a las preferencias alimentarias y su vínculo con una determinada cosmovisión, Guthe (1945: 3), señaló que «los hábitos alimentarios son las elecciones efectuadas por un individuo o grupo de individuos como respuesta a las presiones

${ }^{5}$ La dehesa es un sistema agrosilvopastoril con árboles en grado variable de densidad, pastos herbáceos, cultivos puntuales y ganado en una interacción relativamente sostenible mediante manejos agroganaderos y forestales. Bosque caracterizado por árboles de la familia quercus, sobre todo encinas y alcornoques, cuyo fruto llamado bellota es especialmente apto para que los cerdos ibéricos engorden y su carne adquiera cualidades organolépticas específicas.

${ }^{6}$ Como sabemos, una cosa es lo que se dice y otra la que realmente se hace o piensa, un ámbito es el de las declaraciones y otro el de las prácticas, pero, en cualquier caso, los resultados de este trabajo aportan datos muy significativos avalados por una contrastada metodología. Por otro lado, la percepción puede ser entendida como la visión del mundo de un grupo social, o bien como lo entendemos y usamos aquí, atendiendo a Vargas (1994) que señala que: "la percepción depende de dos aspectos: los estímulos físicos y sensaciones creados por la experiencia y situaciones vividas, y por otro lado de la selección y la organización de dichos estímulos y sensaciones que tienen que ver con la satisfacción de necesidades individuales y colectivas..., que brindan la capacidad para producir pensamientos simbólicos, que se conforma a partir de estructuras culturales, ideológicas, sociales e históricas que orientan la manera como los grupos sociales se apropian del entorno". 
sociales y culturales para seleccionar, consumir y utilizar una fracción de esos recursos posibles". Sobre las razones de las preferencias alimentarias, Contreras (2002), afirmaba que para comprender estas decisiones debemos partir del análisis de la totalidad de la sociedad en la que se producen dichas elecciones, preferencias y prejuicios en torno a los alimentos, puesto que cada cultura crea su propio sistema de comunicación. Dicho sistema elabora nociones firmemente asentadas sobre lo considerado ingerible, digerible, adecuado, cocido, fresco, tóxico, salado, dulce, picante, etc. En cualquier sociedad encontramos reglas no escritas que especifican qué puede comerse y qué no. Parafraseando a Bauman (2010), la elección de la comida en nuestras sociedades actuales sería una decisión más individualizada y motivada por una jerarquía concreta dependiente de clasificar o categorizar los alimentos y sus usos, así como las variables para elegir unos sobre otros.

Por tanto, lo que está cada vez más claro es que el hecho alimentario es multidimensional y requiere del aporte interdisciplinario para ser comprendido y explicado en su globalidad (García 2007; Aguilar, Amaya-Corchuelo y López-Moreno 2016). Es, en el sentido utilizado por Mauss (1994), un hecho social total, entendiendo que todas las áreas de la cultura y, en definitiva, de la vida social (económicas, legales, políticas, religiosas, etc.) encuentran en él expresión simultánea y lo influyen de algún modo. El incremento de los estudios sobre la relación entre cultura y alimentación ha desarrollado líneas de análisis novedosas y renovadoras. Se trata de un corpus documental, etnográfico, conceptual, teórico y metodológico desde la antropología (Aguilar Piña 2014).

Al respecto Espeitx (2005: 124) estableció una similitud entre alimentación y sexo como necesidades fisiológicas que trascienden dicho carácter para aclarar que en ambas es central la apetencia y la búsqueda de placer. Por tanto, el apetito no es solo necesidad, es también deseo, persecución de disfrute y satisfacción ${ }^{7}$.

Así, el placer está estrechamente imbricado con el acto de comer, no solo en el momento de la ingesta, sino también antes, en la espera y los preliminares, y después, por los efectos que produce en el organismo. Los placeres alimentarios, como los sexuales, también se pueden recordar, y proporcionar placer en la evocación (ibid.).

Por tanto, según la autora, el análisis de la multitud de prácticas y expresiones de la ingesta alimentaria, sería una estrategia metodológica para comprender las particularidades en torno a la elección de alimentos en cada sociedad.

Pero esta forma de abordar el hecho alimentario es particularmente escasa. Lo que abundan son los trabajos centrados en los procesos de producción, distribución y consumo alimentario y sus consecuencias en la dinámica social, económica y política (Díaz y Gómez 2005). Es en el consumo donde estos procesos dejan de ser objeto de análisis y no nos dan respuestas sobre qué pasa cuando el alimento alcanza la boca del consumidor. Es decir, es necesario dilucidar los aspectos de la cultura que

\footnotetext{
${ }^{7}$ Brillat-Savarin (1854), en su tratado sobre la Fisiología del gusto planteó que el hecho de alimentarse contempla mayor relación de aspectos. Esa experiencia de alimentarse y de seleccionar un alimento por el sabor y gusto proviene de tres relaciones: lo físico por el simple hecho de apreciar o valorar el sabor, lo moral por la impresión que deja a nuestro mismo organismo y lo material a causa de las sensaciones que se crean.
} 
se expresan en la acción misma de comer un alimento como hecho social. En este sentido Eggan y Pijcan (1943) exponían los problemas que afronta el investigador y que pasaba por alto durante el análisis de la alimentación. De nuevo, como sucedía en el trabajo de Espeitx, su propuesta metodológica nos invita a caracterizar con minuciosidad también los detalles que tienen que ver con el acto de llevarse los alimentos a la boca y su importancia respecto a los hábitos alimentarios, lo cual decanta al consumidor a elegir unos productos sobre otros.

En este sentido cabe mencionar la línea de investigación interdisciplinaria centrada en la percepción del gusto de los alimentos y las condiciones afectivas, psicológicas y sociales por las cuales se aprende a gustar (Jerome 1979; Conner y Booth 1992), incluso tomando en consideración sabores picantes donde las señales de alarma biológica son decodificadas como placer (Rozin y Fallon 1986). Uno de sus referentes fue la influyente obra de Lévi Strauss (2004 [1965]), con su análisis de los códigos alimentarios $^{8}$ y su expresión en cocinas denominadas étnicas.

En esa gran complejidad de los sistemas alimentarios analizados, es importante dilucidar los alimentos básicos de cada cultura como hilos conductores que nos permitirán descifrar esa complejidad (Luhmann 1998). Jelliffe (1967) los denominó "cultural superfood" o superalimento cultural. Los alimentos centrales de cada sociedad proporcionan la mayor parte del valor calórico de la dieta y son los que tienen una fuerte carga simbólica. Así podemos distinguir alimentos periféricos, los consumidos ocasionalmente, en oposición a los superalimentos culturales. Estableciendo una separación clara entre alimentos básicos y secundarios, entendidos los secundarios como no imprescindibles para la alimentación diaria, que bien se pueden expresar en la siguiente figura (Figura 1) adaptada al hecho alimentario:

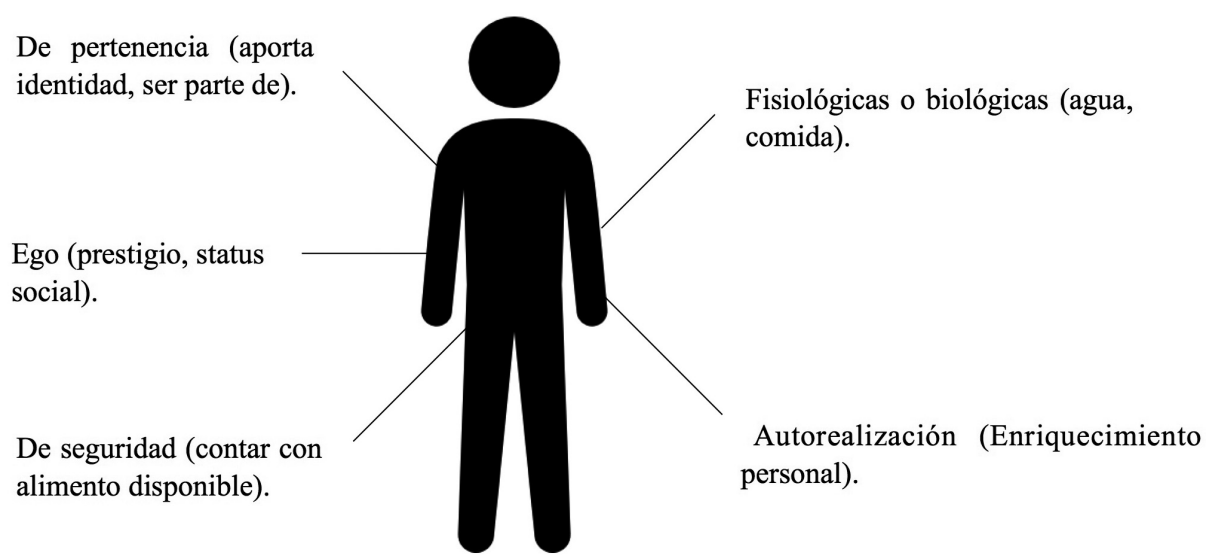

FIgURA 1.- Niveles de necesidades (pirámide de Maslow modificada). Fuente: Elaboración propia basada en Maslow (1962)

\footnotetext{
${ }^{8}$ Las premisas bajo las que este consideró los temas alimentarios, sitúa a los alimentos en el triángulo culinario de lo crudo, lo cocido y lo podrido y cuyas mediaciones centrales pasan por la consideración de las transformaciones culturales y naturales. En relación a ello estableció la tríada de oposiciones básicas: crudo-cocido, sociedad-naturaleza y civilizado-primitivo.
} 
Esta figura nos ubica en las prácticas contemporáneas sobre la alimentación, donde creemos que más que de alimentos secundarios podemos hablar de otro tipo de productos como el caso de los considerados gourmet, aquellos a los que accedemos ocasionalmente y poseen una elevada consideración socioeconómica. Las funciones que cumplen los alimentos gourmet en relación a los alimentos centrales son muy distintas, como lo son el tipo de sociedad a la que se asocia cada uno.

Nuestro trabajo está ampliamente vinculado con las reflexiones de la sociología y antropología al respecto del consumo gourmet, insertas así en lo que Bourdieu (1998) denominó la distinción (no esnobismo) versus lo vulgar en relación al gusto, o Estilos de pensar de Douglas e Isherwood (1979), pasando por la clásica triada de Goody (1995) sobre cocina, cuisine y clase. Son obras donde se analiza el concepto gourmet y su creciente significado en la contemporaneidad alimentaria.

Así, de acuerdo con diversas encuestas sobre las prácticas alimentarias realizadas en varios países (Ascher 2005: 82-104), asistimos a un abandono de los modelos alimentarios tradicionales. Pero por otro lado, existe también una creciente preocupación pública por el alejamiento de las dietas tradicionales y su relación con la pérdida de lo que se entiende socialmente por buena salud. Hay una tendencia a limitar el placer en la comida, pensando que lo saludable es comer menos o bien comer productos que consideramos menos placenteros que otros. Esta tendencia está íntimamente relacionada con una aspiración de controlar el cuerpo a través de la dieta y la actividad física ${ }^{9}$ (Contreras y Gracia 2008). Para Gracia (2010), el hecho de que todos nos preocupemos cada vez más por nuestra dieta y por nuestros comportamientos alimentarios, en busca de la salud, hay que vincularlo poderosamente con la aparición de forma recurrente de los asuntos alimentarios en las agendas políticas desde los años noventa.

Algunos autores hacen hincapié en factores como la comodidad y la salud, como objetivos perseguidos cuando el consumidor elige determinados alimentos. De esta manera y, siempre teniendo presentes el placer y la salud inherentes al hecho alimentario, en los días ordinarios estas variables se activan de forma distinta que en los días festivos. En estos últimos disminuye la preocupación por la salud o por una dieta más sana y aparece un mayor interés por una comida considerada más placentera. Por tanto, existen antagónicas formas de percibir las relaciones entre la salud y el placer. Esta idea fue expresada por algún investigador que llegó a afirmar que "en el futuro el hombre se alimentaría de paquetitos de productos químicos puros, que podría llevar en el bolsillo del chaleco" (Carpenter 2003). Evidentemente no tuvo en cuenta el placer del comer. Sin duda, el placer gastronómico y la búsqueda de lo saludable tienen un papel sustancial en las preferencias alimentarias de nuestras sociedades occidentales.

La relación entre cocinar, comer y socializar es imprescindible en la vida del ser humano (Pollan 2014). Contreras y Gracia (2008) destacan que la cuestión del gusto en el sentido de aceptación/rechazo está también muy marcada por las formas de

\footnotetext{
${ }^{9}$ Asimismo, como lo argumenta Bourdieu (1998), en las dinámicas actuales está muy marcada la influencia de los nuevos intermediarios culturales quienes actúan como transmisores de estilos de vida particulares y donde el estilismo del cuerpo hace referencia a la perfección buscada en la antigua Grecia.
} 
elaboración de los productos mismos y los tiempos que las personas destinan a cocinar. Esto nos suscita algunas preguntas sobre el consumo de jamón ibérico, puesto que al tratarse de un alimento que se consume crudo y su principal presentación es cortado, ¿se puede considerar como un producto no transformado?

La necesidad de recurrir a los aspectos culturales para comprender la alimentación humana se basa en la constatación de que los a priori factores biológicos se concretan de diferente modo en distintas sociedades. Contreras (2002) nos facilita esta afirmación pues: A) existen preferencias y aversiones de unas culturas a otras, en relación con las fuentes de proteínas (insectos, perro, caballo, cerdo, vaca, etc.), que van más allá del hecho biológico y nos remite a estrategias de adaptación al medio; B) en todas las culturas conocidas, las prohibiciones alimentarias parecen más importantes cuando se trata de productos animales que cuando se trata de vegetales, pues, a diferencia de la savia de los vegetales, la sangre de los animales remite a la imagen de la vida humana (Fischler 1995; Lambert 2004); y C) los etnólogos han observado que la carne es el alimento más demandado y en la mayoría de sociedades, la presencia de productos de origen animal en la dieta es tanto más elevada cuanto más alto es el nivel de renta (Harris 1985).

Así, la valoración de la carne es una constante hasta el punto de poder denominar a muchas culturas como porcófilas (Marcos 1989). En este sentido debemos hablar de sociedades y culturas que exaltan la carne de cerdo (porcófilas) y las que lo aborrecen (porcófobas). Tema ampliamente tratado ya por Marcos (1989) y Campillo (2007) para el caso extremeño ${ }^{10}$; por Contreras (2002) al tratar los aspectos culturales en el consumo de carne; y por Rappaport (1987), Leach (1989) o Harris (1985) desde una visión transcultural. Para explicar estos comportamientos alimentarios claramente dicotómicos se han esgrimido argumentos de carácter religioso, ecológico, sanitario. Destacando el Talmud, el Levítico, la Torá, el Corán, como libros sagrados de judíos y musulmanes que prohíben comer carne de cerdo por motivos higiénicos, sanitarios, "por ser perjudicial para la salud", etc., consideran al cerdo como un animal impuro y fuente de contaminación para el cuerpo y el alma. A través de sus creencias y sus textos sagrados una parte del mundo condenó al cerdo, lo convirtió en un tabú alimentario porque su cría constituía una amenaza a la integridad de su medio natural en zonas como Oriente Medio.

Pero como hemos dicho antes, por otro lado existen culturas clara e históricamente porcófilas y estas nos interesan especialmente en la medida que es el contexto donde se desarrollan las prácticas sociales que hemos investigado. Si bien en ellas se sacrifican y consumen otros animales, el cerdo simboliza mucho más que un animal destinado a proporcionar materia prima cárnica. En una sociedad como la extremeña, y por extensión en otras regiones de España, "el cerdo en vida es una criatura profana, que convertida en carnes y alimentos mediante el rito de la matanza, con-

\footnotetext{
${ }^{10}$ Para España habría que referir otros trabajos sobre carne de cerdo y la matanza para contextualizar y complejizar hasta qué punto el cerdo y su carne puede considerarse un superalimento en la terminología de Jeliffe. Entre ellos y solo como ejemplos, el libro Las matanzas: viejas y nuevas estrategias domésticas, de Victoria Quintero Morón (2001); o los artículos La matanza del cerdo en Galicia, de Jesús Taboada (1996) y La matanza del cerdo en Cataluña, de Xavier Fàbregas i Comadran (1996).
} 
junto de prescripciones y proscripciones consuetudinariamente establecidas, se "sacraliza" (Marcos 1989). Para otros autores como Rappaport (1987), el centro mundial del amor a los cerdos se localiza en Nueva Guinea y en las islas Melanesias del Sur del Pacífico. Para las tribus horticultoras de esta región son animales sagrados que se sacrifican a los antepasados y se comen en ocasiones importantes, como bodas y funerales; se sacrifican para declarar la guerra y hacer la paz. El hambre de su carne es tan irresistible entre los vivos y los muertos que de vez en cuando se organizan festines grandiosos y se comen casi todos los cerdos de la tribu de una sola vez.

En España no se realizan sacrificios que diezmen la cabaña de cerdos, aunque asistimos a un posicionamiento claro a favor de los productos tradicionales, de las particularidades culinarias territoriales, del rescate de especies autóctonas, etc. De esta manera se está creando, de acuerdo con Díaz y Gómez (2005), un fenómeno muy particular: la polarización del ámbito agroalimentario como nunca en la historia de la humanidad. En un extremo, el mundo postindustrial con un interés por los productos diferenciados acordes a los nuevos valores sociales de salud, calidad, distintividad, tradición, cultura, medio ambiente y ética (Espeitx 1996; Lozano y Aguilar 2010), es decir, un consumidor de signos. En el otro extremo, el mundo pobre o con consumidores tradicionales donde los alimentos cumplen principalmente una función nutricional y biológica, o como los denominara Jelliffe (1967): superalimentos culturales.

Nuestro análisis se centra en el jamón, por un lado, alimento habitual de culturas tradicionales, producto ordinario de consumo doméstico en muchos casos en forma de autoconsumo (sacrificios domiciliarios) que se origina con la finalidad de preservar la carne de cerdo y poder contar con este alimento todo el año (Catani, Amaya y Díaz 2001: 153-207); pero por otra parte, firmemente asentado en los parámetros del consumo de productos diferenciados y con marca de calidad de las sociedades occidentales, hecho particularmente representado por las Denominaciones de Origen Protegidas (DOP) de este producto (Amaya-Corchuelo y Aguilar 2012). Un producto que puede vincularse al estatus social (Leyva y Pérez 2015).

El consumo de jamón ibérico se encuadra dentro de la cultura alimentaria mediterránea donde, entre otras de sus características, el comer se ha distinguido como un placer compartido. Este, el jamón ibérico, es uno de los alimentos que encaja en estas prácticas compartidas y mediterráneas. Pero es necesario analizar empíricamente en qué medida el consumidor se decanta por el jamón por placer o por salud, dónde y cómo se consume, si es fuente de sociabilidad, etc. A ello nos dedicaremos en estas páginas.

\section{B) JAMÓN, JAMÓN IBÉRICO Y SU RELACIÓN CON LA SALUD}

La palabra jamón parece provenir del francés jambe ('pierna') a jambón. Jamón sería una pierna en francés romance antiguo. El jambón o jamón, propiamente dicho, sería la forma de expresar la calidad y lo agradable al gusto, de una pata de cerdo $^{11}$. El refranero, constructor secular y popular por excelencia, ilustra sobradamente

\footnotetext{
${ }^{11}$ Información proveniente del blog (Blogjamoniberico 2012): <https://blogjamoniberico.wordpress. com/2012/02/29/el-nombre-de-pila-del-jamon-iberico-se-sabe-galo/>.
} 
la relación de este alimento ${ }^{12}$ con el placer: Jamón de Aracena, es cosa buena; o bien, En Azuaga, lechones, en Berlanga, melones, y en ambos, buenos jamones. Mucho más rotundos son otros refranes que señalan que el jamón supone un gran beneficio para la salud: Quien toma vino y jamón, no padece del corazón; Tinto con jamón es buena inyección; Jamón y vino añejo, estiran el pellejo. Hasta el punto de que no solo constituyen un método para mejorar alguna enfermedad, la circulación sanguínea o la piel, sino incluso puede acercarse a lo milagroso: Olla con jamón y gallina, a los muertos resucita.

Regresando a los estudios actuales sobre las preferencias de los consumidores españoles, algunos señalan cómo las personas asocian las comidas "más sabrosas", "más placenteras" con los alimentos más grasos y las preparaciones "más pesadas" y ambas categorías — "grasas", "pesadas" — se consideran las más perjudiciales para la salud (Contreras y Gracia 2008). Sin embargo, el jamón ibérico, que bien puede incluirse en el grupo de alimentos grasos y/o pesados, trasciende absolutamente dicha consideración social para instalarse en el ideario colectivo como saludable, de acuerdo con lo que comprobamos con el refranero. Un estudio contemporáneo al respecto como el de ASICI (2009), señala que el $95 \%$ de la muestra considera el jamón como un producto benéfico para la salud.

Esta asociación deviene fundamentalmente de la relación salud con raza de cerdo ibérico. Esta raza desarrolla una grasa que se infiltra en depósitos subcutáneos (tocino), intermusculares (manteca y otras) e intramusculares (veteado). La composición de estas grasas está fundamentalmente determinada por la alimentación del cochino, resultando que los cerdos alimentados en montanera ${ }^{13}$ poseen un alto contenido de grasas monoinsaturadas y poliinsaturadas (Pérez, Ruiz y Antequera 2008). Además, tienen un punto de fusión muy bajo (entre $32^{\circ}$ y $36^{\circ}$ centígrados). Este es un detalle muy importante a tener en cuenta, ya que es responsable de la buena difusión de los aromas que son liposolubles, que al combinarse con altas temperaturas externas, los aromas y sabores se incrementan. De ahí que las personas entrevistadas mencionaban la importancia de la experiencia de consumir este producto bajo las condiciones ambientales locales.

El jamón ibérico ${ }^{14}$ está reconocido dentro del ámbito culinario occidental como uno de los grandes placeres para el gusto, particularmente si es de bellota, aunque conlleve un sobrecoste para el consumidor. Es posible interrogarse sobre si realmente el jamón que se consume cotidianamente tiene impactos o relación directa con la salud de quien lo consume ${ }^{15}$. Sus saludables ventajas pueden ser de distinto tipo (Tabla 1):

\footnotetext{
${ }^{12}$ Jamón en general, sin distinguir entre sus variedades, tipos o singularizar si se trata de ibérico o serrano.

${ }^{13}$ Temporada de maduración de las bellotas y fase de engorde del cerdo mediante bellotas.

${ }^{14}$ Los jamones de cerdo ibérico se presentan siempre como una pieza alargada, estilizada, predominando la longitud sobre la anchura. Por su parte externa y mirando al jamón colgado, el cuero o piel está cortado en forma de V; va recubierto de escaso tocino y siempre su presentación es con pezuña, generalmente negra.

${ }^{15}$ ¿Es aconsejable que coma jamón, por muy ibérico que sea, un hipertenso, alguien con insuficiencia cardiaca congestiva u otro tipo de afecciones cardiovasculares?
} 


\section{Beneficio graso}

La grasa del cerdo ibérico de montanera posee un alto contenido en ácido oleico (ácido graso monoinsaturado presente en el aceite de oliva ${ }^{16}$ ), así como de ácidos grasos poliinsaturados. La proporción que contiene de ácidos grasos saturados, monoinsaturados y poliinsaturados, lo que unido al bajo contenido en colesterol, se corresponde con lo que puede entenderse como "grasa saludable" en lo que respecta a su repercusión sobre el riesgo de sufrir enfermedades cardiovasculares ${ }^{17}$. Según Campillo (2007) «el consumo diario de 120 gramos de jamón ibérico en una población cerrada y controlada disminuye significativamente los niveles de colesterol y triglicéridos".

\section{Beneficio antioxidante}

El beneficio de su consumo para los huesos resulta que el jamón es rico en vitamina E, un poderoso antioxidante, y en minerales como el cobre, esencial para los huesos y cartílagos, además de calcio, hierro, zinc, magnesio, fósforo y selenio, este último muy ligado a procesos de antienvejecimiento.

\section{Beneficio vitamínico}

El jamón ibérico contiene vitaminas B1, B6, B12 y ácido fólico, necesarias para el buen funcionamiento del sistema nervioso.

\section{Beneficio cardiovascular}

Cuida el contenido en calorías de la dieta. 100 g de jamón ibérico de bellota aportan menos de $250 \mathrm{kcal}$ (más o menos como el pan blanco), por lo que un consumo moderado puede ser compatible con dietas bajas en calorías. Del mismo modo constituye una buena fuente de aporte de proteínas: $100 \mathrm{~g}$ de jamón contienen $43 \mathrm{~g}$ de proteínas.

TABla 1.-Beneficios en el consumo de jamón ibérico. Fuente: Elaboración propia basada en Campillo (2007), Pérez, Ruiz y Antequera (2008) y OCN FENACO (2014)

La vinculación de este producto con la salud en general y particularmente con aspectos cardiovasculares ${ }^{18}$ es notoria. No obstante, estos beneficios positivos pudieran ser lo contrario si la dieta que se sigue es sobre todo con alto consumo de cárnicos, grasas y otros tipos de proteínas. Los valores nutricionales se pueden disparar y ocasionar estragos en la salud, lo cual no es óbice para que constituya un lugar común de la mercadotecnia de jamón ibérico (Amaya-Corchuelo y Aguilar 2012).

Hay que tener en cuenta que la mayor parte de jamón que se vende no comparte las bondades que señalamos, pues de los jamones comercializados en 2015 en las grandes superficies el $81.38 \%$ correspondió a jamón curado de cerdo blanco y $18.62 \%$ a jamón ibérico (Martínez 2015). Dentro de este último grupo de jamón ibérico, un porcentaje que no sobrepasa el $10 \%$ del total procedía de cerdos alimentados con bellotas. Un gráfico del sacrificio de cerdos en el país (Gráfico 1) nos dará una precisa perspectiva cuantitativa sobre el sector porcino general y del sector porcino ibérico en particular.

${ }^{16}$ Se dice que "el cerdo ibérico es un olivo con patas".

${ }^{17}$ Es indudable que desde el punto de vista de la composición en grasas no es en absoluto perjudicial, pero no se debe olvidar que el contenido de sal, en pacientes hipertensos o con otros problemas cardiovasculares o renales, es una bomba de relojería. De cualquier modo, dietas basadas en el consumo de jamón para mejorar peso y salud se dan desde el ámbito científico. Véase OCN FENACO (2014).

${ }^{18}$ Véase por ejemplo la web de una conocida marca de jamón y sus mensajes sobre salud y bienestar: <http://www.montesierra.es/blog/dia-mundial-corazon-jamon-iberico-montesierra/>. 


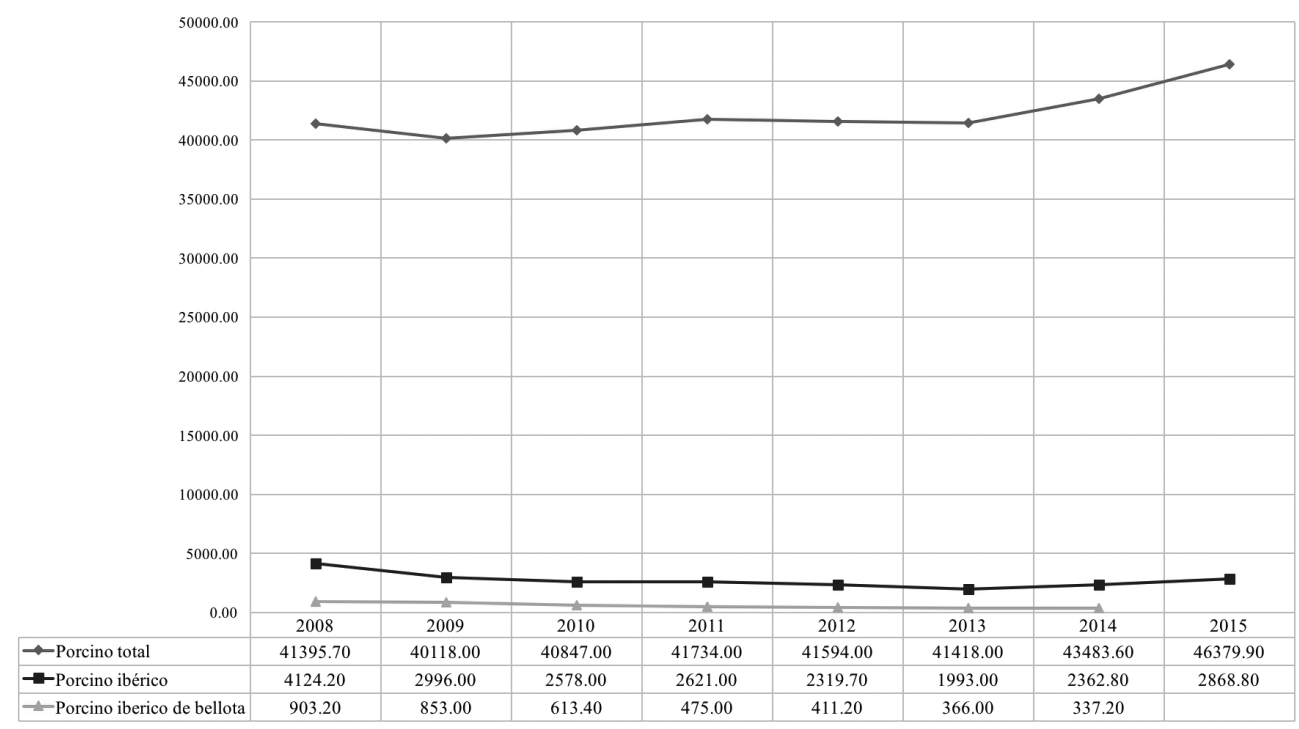

GRAFICO 1.-Evolución de sacrificios del sector porcino español ${ }^{19}$.

Fuente: Elaboración propia basada en MAPAMA (2016)

La realidad es que existe un ingente sector cárnico porcino de capa blanca ante el que el ibérico es casi insignificante. Es más, dentro del mismo, los cerdos ibéricos de bellota, a su vez, son numéricamente poco representativos. Pero es en este pequeño nicho productivo donde se construyen los valores relacionados no solo con la calidad del producto (Amaya-Corchuelo 2015), sino también con la salud, como venimos señalando.

Otra interesante lectura cualitativa de la relación entre jamón ibérico de bellota y salud, es la que nos ofrecen nuestros informantes, los consumidores:

en un jamón te estás gastando 300. Por no pagar 32 euros, llevarte un jamón que a lo mejor no lo es [de bellota]. Me voy a un litro de aceite... a lo mejor la diferencia [entre el mejor y otros] son 60 céntimos. ¿Merece la pena? Depende de dónde tenga puesto cada uno su estándar. Yo soy una persona muy responsable de lo que le doy de comer a mis hijos, porque la salud entra por la boca. Si te lo puedes permitir económicamente hablando para dárselo a tus hijos, no solamente para disfrutar de la gastronomía, sino como una cuestión de salud. ...Y sé que el de bellota no es solo mejor gastronómicamente hablando, sino que es mejor desde el punto de vista de la salud (Consumidor, entrevista personal, 14 may. 2016).

Pero haciendo referencia a los sentidos que despierta el consumo de jamón ibérico de bellota, tal como estamos señalando, los informantes reconocen múltiples y definitivas sensaciones:

\footnotetext{
${ }^{19}$ Las cantidades están expresadas en millones de cabezas sacrificadas y para el caso del ibérico de bellota, en miles de cabezas. Para el año 2014 aún no existen datos oficiales, y del año 2015 todavía no hay cifras.
} 
cuando estás cortando el plato pues se disfruta con los cinco sentidos. Te imaginas el sonido de estar en la dehesa, sin ruido y escuchando esta agua de fondo, tienes que mirar la loncha, tiene que estar brillando, debe de estar como sudando, eso te habla del tipo de grasas que tiene... pero no es agresivo, te aporta muchísimo. Es como una explosión de sabores. Me decía el otro día un italiano: "esto parece un orgasmo". Un montón de sensaciones y experiencias en un segundo (Consumidor, entrevista personal, 2 mar. 2016).

\section{METODOLOGÍA MIXED MODE}

En el proceso metodológico utilizado en este trabajo hemos tenido en cuenta las dinámicas de producción, comercialización y consumo del jamón ibérico en España. De esta forma se dividieron a los actores sociales en tres subgrupos para ser tratados de forma independiente: (1) actores clave de la cadena agroalimentaria; (2) industriales de jamón ibérico; y (3) consumidores de jamón ibérico residentes en España. Inicialmente realizamos un análisis de fuentes documentales, observación participante y 54 entrevistas en profundidad semidirigidas a informantes clave de la zona estudio ${ }^{20}$. Dicha información cualitativa fue la base para elaborar las categorías de análisis de los cuestionarios tanto para industriales como consumidores de jamón ibérico.

Para obtener los datos cuantitativos correspondientes a los industriales y consumidores, se aplicó un enfoque mixto ${ }^{21}$ con apoyo tecnológico, empleando técnicas como CATI (Computer Assited Telephone Interview) y CAWI (Computer Assisted Web Interview). Por un lado, en el caso del sector de industriales de jamón se comenzó con la ubicación y validación de la zona de producción a partir del registro oficial del RGSEAA (Registro General Sanitario de Empresas Alimentarias y Alimentos), bajo el epígrafe "Salado y secado de jamones". Tras el contraste de dicha información con la del Registro Sanitario de España y otras fuentes ${ }^{22}$, obtuvimos una base de datos con 682 registros de industriales de jamón. Teniendo en cuenta que la población era finita, se aplicó el instrumento de análisis a toda la población. Fue una encuesta de carácter nominal, dirigida y personalizada mediante cuestionario web autoadministrado.

En otro sentido al analizar a los consumidores, las características del servicio de telefonía móvil en España y su extensión prácticamente universal en la población ${ }^{23}$, hicieron factible la realización de encuestas a los consumidores de jamón a través de

\footnotetext{
${ }^{20}$ Las entrevistas fueron realizadas a ganaderos de cerdo ibérico, industriales de jamón, representantes de Grupos de Desarrollo Local, agentes comerciales, Secretarios de las DOP de jamón y organismos interprofesionales del sector, principalmente.

${ }^{21}$ Según De Leeuw (2005) y Dillman, Smyth y Christian (2014), existen dos tipos de metodologías que permiten combinar técnicas dependiendo el resultado deseado, estas son el modo mixto y el multimodal (multi-mode). En este estudio se utilizó un modo mixto donde la combinación de técnicas empleadas tuvieron la misma jerarquía.

${ }^{22}$ La BD se construyó a partir de varios directorios: AECOSAN (Agencia Española de Consumo, Seguridad Alimentaria y Nutrición), MAPAMA (Ministerio de Agricultura y Pesca, Alimentación y Medioambiente), <infobel.com>, <alimarket.es>, <dehesa-extremadura.com>, <origenguijuelo.com>, $<$ jamondehuelva.es $>$ y <jamonlospredoches.es $>$. De esta forma se generó una base de datos con más de 1600 registros. El criterio de discriminación utilizado en esta primera lista fue que produjeran jamón ibérico y/o jamón ibérico de bellota.

${ }^{23}$ Según datos del Instituto Nacional de Estadística de España (INE) en 2015 el 96,7\% de la población española usa teléfono móvil (INE 2015).
} 
líneas móviles. La población objetivo fue la de los consumidores reales y potenciales de jamón ibérico. La muestra representativa que se estimó fue de $n=800$ consumidores con un nivel de confianza del $95 \%$ y un margen de error del $5 \%$. En el proceso de muestreo se ha usado la técnica de RDD (Random Digital Dialing), es decir, marcación al azar de entre todos los rangos posibles de teléfonos. La recogida de datos se realizó mediante CATI y CAWI. La aplicación se realizó durante los meses de noviembre y diciembre de 2015. La encuesta fue de carácter nominal, dirigida a cada consumidor real o potencial, mediante cuestionario Web auto administrado y por teléfono móvil, siendo la muestra final de $n=805$ cuestionarios completos $^{24}$. En el caso de los consumidores reales entrevistados y según sus valores sociodemográficos ${ }^{25}$, podemos afirmar que representan fielmente a la sociedad española.

\section{RESULTADOS Y DISCUSIÓN}

Para iniciar nuestro análisis partiremos de una visión global sobre consumidores de jamón ibérico en España. Los datos nos confirman que de 805 personas entrevistadas, no comen jamón ibérico 236 de ellas (30\%) y sí lo consumen 569 (70,7\%). Por tanto, el grupo compuesto por 569 personas son los consumidores reales, lo que equivale a que en la población española, algo más del $70 \%$ es consumidora de jamón ibérico alguna vez al año ${ }^{26}$. En línea con los resultados generales de nuestro trabajo, hay que señalar también que era prioritario conocer y partir de la percepción más extendida y genérica sobre un producto como el jamón, con todas las implicaciones culturales que un alimento tan polisémico tiene. De este modo, si nos centramos concretamente en los resultados de la técnica de libre asociación de palabras, al preguntarles cuál es la primera palabra que le viene a la mente cuando escuchan jamón ${ }^{27}$, resultan términos tremendamente variados. En las dos figuras siguientes (Figura 2) se puede observar gráficamente la discordancia de términos posicionados en el subconsciente del grupo de industriales y del grupo de consumidores.

${ }^{24}$ Es importante aclarar que la muestra final fue de $n=805$ consumidores, sin embargo para algunas categorías de análisis se tiene mayor o menor frecuencias de respuestas debido a que algunas personas solo respondieron alguna parte de la encuesta. En este sentido se diseñó el instrumento a aplicar por secciones y para no generar un posible sesgo, solo se utilizarán frecuencias mayores derivadas de la primera sección correspondiente a preguntas abiertas. Esta es la sección de la libre asociación de palabras.

${ }^{25} \mathrm{Al}$ comparar los valores sociodemográficos de edad, género y distribución poblacional, no existe diferencia significativa con respecto a la población general de España. Por lo cual se puede afirmar que la muestra es fiel reflejo de la población.

${ }^{26}$ Si bien hemos considerado consumidor a quien consume jamón al menos una vez al año, somos conscientes de que este tipo de consumo, escaso, nos remite a cierta universalización del consumo de jamón, pero no a su consumo con cierta constancia. Sin embargo, los consumidores cuya frecuencia es más habitual constituyen el grueso de los informantes y así se justifican ampliamente los datos obtenidos y analizados aquí.

${ }^{27}$ En el análisis categórico se intentó evitar el uso conjunto del término jamón ibérico para no incidir en la posible respuesta, por ello solo se decía jamón. De igual forma se colocó la pregunta al inicio del cuestionario para evitar influir en la respuesta. 


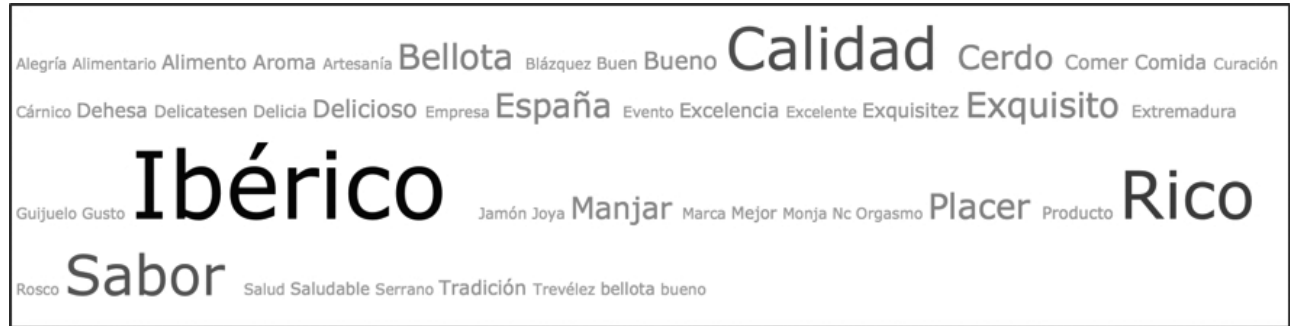

Bellota Bocadillo Buen Buena
Comida Delicioso España Exquisito Grasa Gusto Hambre Ibérico Jabugo Jamón Manjar Matanza Me Monja Muy Nada
boca bueno encanta gusta me negra rico sabe

FIGURA 2.-Primera palabra que le viene a la mente al escuchar jamón ${ }^{28}$ : a) nube de industriales; y b) nube de consumidores. Fuente: datos del trabajo de campo

Sin embargo, los primeros cinco términos, con base en sus frecuencias de mención, representan cerca del 40\% de todas las palabras aludidas (Tabla 2). Las demás palabras contestadas son muy variadas pero con significados o raíces similares que, de acuerdo con Guerrero et al. (2010), se pueden agrupar y analizar en clases mediante una triangulación de los términos. Esta agrupación permite relacionar las respuestas de industriales y consumidores de jamón con criterios más amplios asociados a significados generales ampliamente compartidos en la sociedad (Tabla 3).

\begin{tabular}{|l|c|l|c|}
\hline \multicolumn{2}{|c|}{ INDUSTRIALES } & \multicolumn{2}{c|}{ CONSUMIDORES } \\
\hline TÉRMINO & FRECUENCIA & TÉRMINO & FRECUENCIA \\
\hline Ibérico & 31 & Bueno & 93 \\
\hline Rico & 22 & Rico & 83 \\
\hline Calidad & 19 & Cerdo & 80 \\
\hline Sabor & 18 & Ibérico & 50 \\
\hline Bellota & 11 & Sabor & 41 \\
\hline
\end{tabular}

TABLA 2.-Primeras cinco palabras mencionadas en las respuestas ${ }^{29}$. Fuente: datos del trabajo de campo

\footnotetext{
${ }^{28}$ El tamaño del carácter que conforma la palabra, depende del número de personas que respondieron esa misma palabra. A mayor tamaño, más personas dieron esa respuesta.

${ }^{29}$ Las cantidades están expresadas en el número de personas que respondieron ese término.
} 


\begin{tabular}{|l|l|l|}
\hline \multicolumn{1}{|c|}{ PALABRAS MENCIONADAS } & \multicolumn{1}{|c|}{ DEFINICIÓN DEL GRUPO } & \multicolumn{1}{|c|}{ GRUPO PROPUESTO } \\
\hline $\begin{array}{l}\text { Alimento, embarazo, engordar, } \\
\text { grasa, magro, natural, proteínas, } \\
\text { salud, sano, vegetariano, vida. }\end{array}$ & $\begin{array}{l}\text { Argumento relacionado con la } \\
\text { salud del ser humano, puede ser } \\
\text { término positivo o negativo. }\end{array}$ & Salud \\
\hline $\begin{array}{l}\text { Delicioso, buenísimo, exquisito, } \\
\text { me encanta, placer, me gusta, ri- } \\
\text { quísimo, sabor, sabroso, salado, } \\
\text { orgasmo, delicia, alegría, manjar. }\end{array}$ & $\begin{array}{l}\text { Hedonismo antes, durante y des- } \\
\text { pués de degustar. Una valora- } \\
\text { ción del producto en cuanto al } \\
\text { placer por comprarlo y consu- } \\
\text { mirlo. Relación con el ego. }\end{array}$ & Placer (Hedónico) \\
\hline $\begin{array}{l}\text { Calidad, carísimo, caro, maravi- } \\
\text { lloso. }\end{array}$ & $\begin{array}{l}\text { Adjetivo calificativo sobre el pro- } \\
\text { ducto, sin relación directa con la } \\
\text { degustación. }\end{array}$ & Valoración \\
\hline $\begin{array}{l}\text { 5 Jotas, Joselito, Navidul, olor, } \\
\text { oscuro, rojo, pata negra, precio. }\end{array}$ & $\begin{array}{l}\text { Palabras relacionadas con aspec- } \\
\text { tos externos del producto. }\end{array}$ & Atributos extrínsecos \\
\hline $\begin{array}{l}\text { Aceite, amigos, bocadillo, cerve- } \\
\text { za, celebración, comer, desayu- } \\
\text { no, diario, melón, vino, tinto. }\end{array}$ & $\begin{array}{l}\text { Las maneras, formas, acompaña- } \\
\text { mientos o lugares de consumir } \\
\text { jamón. }\end{array}$ & Formas de consumo \\
\hline $\begin{array}{l}\text { Andalucía, Guijuelo, bellota, cu- } \\
\text { ración, serrano, propio, pueblo, } \\
\text { ibérico. }\end{array}$ & $\begin{array}{l}\text { Lugar de procedencia, materia } \\
\text { prima para elaborar, técnica, te- } \\
\text { rritorio posicionado. }\end{array}$ & Origen/identidad \\
\hline
\end{tabular}

TABLA 3.-Agrupación de palabras tanto para industriales como consumidores. Fuente: datos del trabajo de campo

Los porcentajes de mención para cada grupo quedan distribuidos en la Tabla 4, toda vez que se recuerda que el número de respuestas recogidas: consumidores una muestra de $n=872$ e industriales $n=259^{30}$. Este dato es de relevancia para la interpretación de los gráficos al estar expresados en porcentajes de respuesta por cada agrupación elaborada.

\begin{tabular}{|l|c|c|c|}
\hline \multicolumn{1}{|c|}{ GRUPO DE PALABRAS } & $\begin{array}{c}\text { PORCENTAJES } \\
\text { INDUSTRIALES }\end{array}$ & $\begin{array}{c}\text { PORCENTAJES } \\
\text { CONSUMidORES }\end{array}$ & DifERENCIAS \\
\hline Salud & 1,94 & 2,59 & 0,65 \\
\hline Placer (Hedónico) & 40,70 & 43,75 & 3,05 \\
\hline Valoración & 14,74 & 6,37 & 8,37 \\
\hline Aspectos extrínsecos & 3,49 & 2,83 & 0,66 \\
\hline Formas de consumo & 5,81 & 13,8 & 7,99 \\
\hline Origen/identidad & 33,72 & 30,66 & 3,06 \\
\hline
\end{tabular}

TABLA 4.-Porcentajes de mención por grupo de palabras ${ }^{31}$.

Fuente: datos del trabajo de campo

\footnotetext{
${ }^{30}$ El número representa el total de personas que respondieron solo a esta categoría de análisis. Esta sección se colocó al inicio como estrategia para recabar el mayor número de respuestas posibles de aquellas personas que no continuaran el cuestionario.

${ }^{31}$ Cantidades expresadas en porcentajes, incluidas las diferencias.
} 
Según estos datos ${ }^{32}$, lo más destacable corresponde a la respuesta que dieron nuestros informantes para definir mediante pocos términos qué es realmente el jamón para ellos, y ahí resulta dominante su vinculación con el término placer. Por otro lado, en este tipo de asociación de palabras sobre la consideración hacia el jamón hay que comentar la importancia para los entrevistados de los términos identidad y origen (más de un $30 \%$ ). Finalmente es muy destacable, para consumidores y para industriales, la escasa relevancia de una variable central en este trabajo como la salud, apenas un $2 \%$. Su explicación tiene que ver con que las respuestas y resultados analizados aquí, corresponden a una pregunta sobre la percepción general en torno al jamón (sin especificar el tipo), no sobre jamón ibérico específicamente.

La estrategia de haber preguntado solo sobre jamón, sin el apellido ibérico, tiene su lógica. De esta forma, se colocó la pregunta en la primera sección para evitar incidir en la respuesta del encuestado. La redacción de la pregunta se elaboró de tal forma que evitaba el uso de algún término como ibérico, bellota, dehesa, pata negra o cualquier otro que pudiera influir a las personas encuestadas. Esta estrategia fue desarrollada porque de acuerdo a las entrevistas en profundidad, dichas palabras están intrínsecamente relacionadas con el producto en estudio. Así, el encuestado, ya sea industrial o consumidor, pudo responder con las palabras posicionadas en su subconsciente. Esto no corresponde a un sesgo, sino todo lo contrario, refuerza el estudio y la idea sobre el posicionamiento de este producto en las personas.

A continuación, en las secciones posteriores del cuestionario, la variable salud toma relevancia a la hora de preguntar y vincular al jamón con las palabras ibérico y bellota. Esta estrategia resultaba importante al considerar los argumentos de las entrevistas en profundidad, donde los actores resaltaban que la calidad en contenido de ácidos grasos corresponde únicamente al jamón ibérico y de bellota. En el cuestionario aplicado específicamente a los informantes consumidores se preguntaba sobre una serie de variables en torno a los hábitos de compra y de consumo de jamón ibérico (no de otro tipo de jamón).

Los datos demuestran gráficamente que la importancia para consumir jamón ibérico se basa por orden decreciente en estas razones: placer, calidad y salud. Es la variable del gusto o placer que proporciona un alimento como el jamón el valor que supera a todas las demás. En este caso, tal como se puede contemplar en la Tabla 5,

\begin{tabular}{|l|r|r|r|r|r|}
\hline \multicolumn{1}{|c|}{ CATEGORÍA } & NADA IMPORTANTE & \multicolumn{1}{c|}{2} & \multicolumn{1}{c|}{3} & \multicolumn{1}{c|}{4} & MUY IMPORTANTE \\
\hline Parte de su identidad & $\mathbf{1 0 3}$ & 98 & $\mathbf{1 5 5}$ & $\mathbf{1 2 0}$ & 99 \\
\hline Le gusta & 4 & 5 & 45 & $\mathbf{1 2 9}$ & $\mathbf{3 9 4}$ \\
\hline Alimento saludable & 4 & 26 & $\mathbf{1 1 1}$ & $\mathbf{1 7 1}$ & $\mathbf{2 6 5}$ \\
\hline Alimento de calidad & 4 & 10 & 90 & $\mathbf{1 4 7}$ & $\mathbf{3 2 6}$ \\
\hline Consumo aporta prestigio & $\mathbf{1 1 7}$ & 75 & $\mathbf{1 2 6}$ & $\mathbf{1 3 0}$ & $\mathbf{1 2 7}$ \\
\hline Importante en dieta & 74 & $\mathbf{1 0 5}$ & $\mathbf{1 7 8}$ & $\mathbf{1 2 4}$ & $\mathbf{9 4}$ \\
\hline Cotidiano en su hogar & 68 & $\mathbf{1 2 2}$ & $\mathbf{1 5 4}$ & $\mathbf{1 2 3}$ & $\mathbf{1 0 9}$ \\
\hline
\end{tabular}

TABLA 5.- Razones de consumo de jamón ibérico.

Fuente: datos del trabajo de campo

\footnotetext{
${ }^{32}$ Los valores negativos se refieren a una mayor respuesta en esa agrupación de palabras de parte del consumidor, mientras que las diferencias positivas aluden a que los industriales ofrecieron mayor número de respuestas en esta categoría.
} 
donde a partir de la adaptación de las necesidades de Maslow (2013), las estrategias de Solomon et al. (2006), el estudio realizado por ASICI (2009) y según las entrevistas en profundidad, se establecieron estas siete categorías de análisis para cuantificar su importancia para los consumidores de jamón. De ahí que son 394 personas quienes dan mayor valor al gusto o placer, lo que representa mucho más de la mitad de los consumidores de jamón ibérico.

Inmediatamente es obligado comentar la importancia del aspecto salud como una destacadísima razón del consumo de jamón ibérico en la sociedad española, tal como referimos en otros apartados. Si bien, las primeras lecturas basadas en los datos iniciales procedentes de la respuesta de los informantes sobre qué era o representaba el jamón para ellos la salud resultó un valor insignificante (en torno al 2\%), ahora el valor salud ha sido mencionado por 265 informantes (cerca del 50\%). Solamente es superado por dos valores, placer y calidad.

Este hecho que puede parecer a priori una contradicción a la vista de los datos, puede explicarse en cierto modo si pensamos que los informantes en el primer caso respondían sobre la idea y el estereotipo del jamón como un producto genérico ${ }^{33}$, tal como comentamos ya, mientras que en este caso estaban respondiendo específicamente sobre jamón ibérico. Un producto considerado no solo como el de máxima calidad dentro del sector de embutidos o carnes curadas, sino estereotipado como saludable por excelencia. Es interesante hacer este contraste, ya que por un lado inconscientemente los consumidores relacionan solo al término jamón con percepciones hedónicas unidas al apellido ibérico. Por el otro, al puntualizar y dirigir la pregunta hacia el jamón ibérico en específico, su percepción se dispara y los valores cambian relativamente, ponderando la relación con la salud. Desde esta perspectiva resalta el vínculo cultural del jamón ibérico para la sociedad española, demostrando que el placer, la calidad y la salud son elementos clave en la percepción de los consumidores sobre el jamón ibérico.

Si contrastamos nuestros datos relativos a la vinculación del consumo de jamón con salud, un referente es el estudio realizado por ASICI en 2009. Su objetivo fue analizar el vínculo del jamón ibérico con la salud en la sociedad española, resultando que cerca del $95,05 \%$ de los encuestados consideraban el jamón como un producto sano. Como hemos visto, según nuestros datos solo cerca de $50 \%$ de la muestra atribuye importancia a la salud. Esto difiere del estudio de ASICI por dos razones fundamentales: A) la primera y más importante es que en nuestro estudio se evitó el uso de una variable dicotómica y se empleó una escala Likert, además de aleatorizar el orden de respuesta que evitaba el efecto de aquiescencia; y B) el segundo es que la redacción de la misma pregunta ${ }^{34}$ de ASICI incide en la respuesta afirmativa, lo cual quedaría sesgada hacia una alta respuesta en el valor "sí".

Pero es momento de lecturas específicas, particularmente sobre los consumidores. Más arriba señalamos que prácticamente un $70 \%$ de la población española es consumidora de jamón ibérico. Ahora bien, entendiendo como consumidor aquella persona

\footnotetext{
${ }^{33}$ En este caso, con base en parámetros culturales de España, se podría estar pensando en el jamón curado blanco, jamón york, jamón serrano, jamón ibérico, entre otros que conforman la amplia gama de producciones que reciben este apelativo y que tiene una fuerte presencia en la mesa del consumidor.

${ }^{34}$ ¿Consideras qué el jamón ibérico es un alimento saludable?
} 
que come jamón ibérico al menos una vez al año, es muy revelador considerar también la periodicidad o frecuencia de su consumo entre los españoles. En este sentido, como se desprende de la Figura 3, casi un $7 \%$ de consumidores lo come a diario y semanalmente en torno a una cuarta parte, lo que nos da idea de que estamos ante un producto alimentario secundario, por así decirlo, donde la elección de consumirlo no tiene relación con una necesidad biofisiológica, sino de degustación y placer.

Pero llegados aquí es imprescindible aclarar un aspecto sobre el consumo gourmet de jamón ibérico. El consumo gourmet, entre otras cuestiones, se caracteriza por ser exclusivo y minoritario. En el caso de jamón ibérico, acorde a la cifra de que un $70 \%$ de la población española es consumidora de jamón ibérico, podemos hablar de su universalización. Ahora bien, esto no invalida al producto y su consumo como gourmet, en tanto en cuanto existe un sector minoritario que consume jamón ibérico de bellota (producto reducido y caro). En ese segmento de producto (jamón ibérico de bellota), de consumo (reducido y caro), se ubica el consumidor y el consumo gourmet.

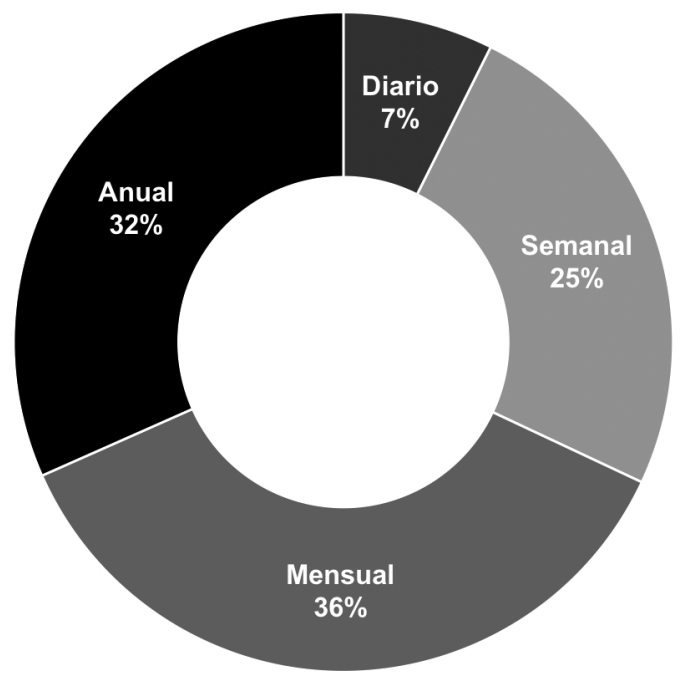

Figura 3.-Frecuencias de consumo de jamón ibérico. Fuente: datos del trabajo de campo

Al cruzar las variables de frecuencia de consumo y procedencia de los encuestados, podemos comprobar si hay una relación identitaria directa entre el hecho de elegir un jamón ibérico y provenir de una zona productora. Resulta sorprendente que en el NUTS (4) ${ }^{35}$ del Gráfico 2, en esta región considerada histórica y culturalmente ligada

\footnotetext{
${ }^{35}$ La Unión Europea ha creado una nomenclatura común de unidades territoriales estadísticas, NUTS, con el objetivo de permitir la recopilación, generación y difusión de estadísticas regionales armonizadas en la Unión. Este sistema jerárquico sirve también para los análisis socioeconómicos de las regiones y para la formulación de las intervenciones en el contexto de la política de cohesión de la Unión. España se encuentra dividida en 7 NUTS y en el presente estudio se tomaron como base de análisis.
} 
a la producción de jamón ibérico, su consumo diario $(2,7 \%)$ está muy por debajo del consumo medio de la población española (7,2\%). Mientras que el NUTS (1), zona sin presencia de producción de jamón, el consumo diario se encuentra por encima de la media (11,8\%). Asistimos de esta forma a una posible relación del consumo de jamón ibérico con el nivel de renta. En el consumo mensual y anual sobresalen el NUTS (3) y NUTS (7) respectivamente. De igual forma el consumo semanal es relativamente similar, pero en Canarias está ligeramente por debajo de la media.

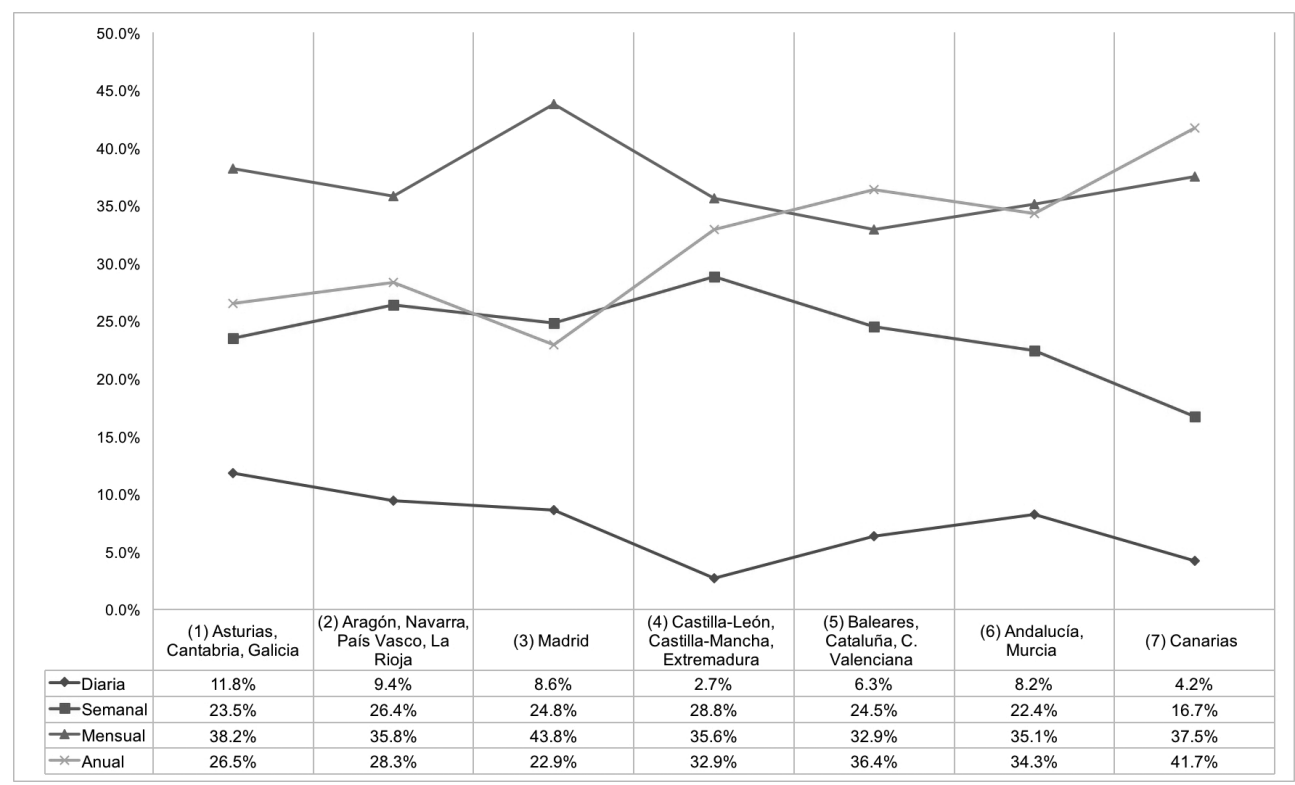

GRÁFICO 2.-Frecuencias de consumo por NUTS (1) de la UE. Fuente: datos del trabajo de campo

Podría pensarse que la variable identitaria determina la mayor frecuencia de consumo, pero según la gráfica no es así, el consumo real está mayormente relacionado con el poder adquisitivo. Recordemos que cuando hablamos de jamón ibérico es imprescindible tener en cuenta que su consumo comporta estatus social en la medida que se trata de un producto gourmet. Los datos sobre estatus social o poder adquisitivo, según el Gráfico 3 en la línea semanal, constatan que el grado de consumo semanal se incrementa cuanto mayor es el nivel de ingreso de los consumidores; por el contrario, el nivel de consumo anual es mayor cuando el ingreso es más bajo. Mientras que el consumo diario se comporta similar en todos los estratos. Lo cual refuerza claramente una idea central aquí, que existe un consumo de jamón ibérico en el país tendente a la selección gourmet, mucho más que como un consumo de un producto de primera necesidad. 


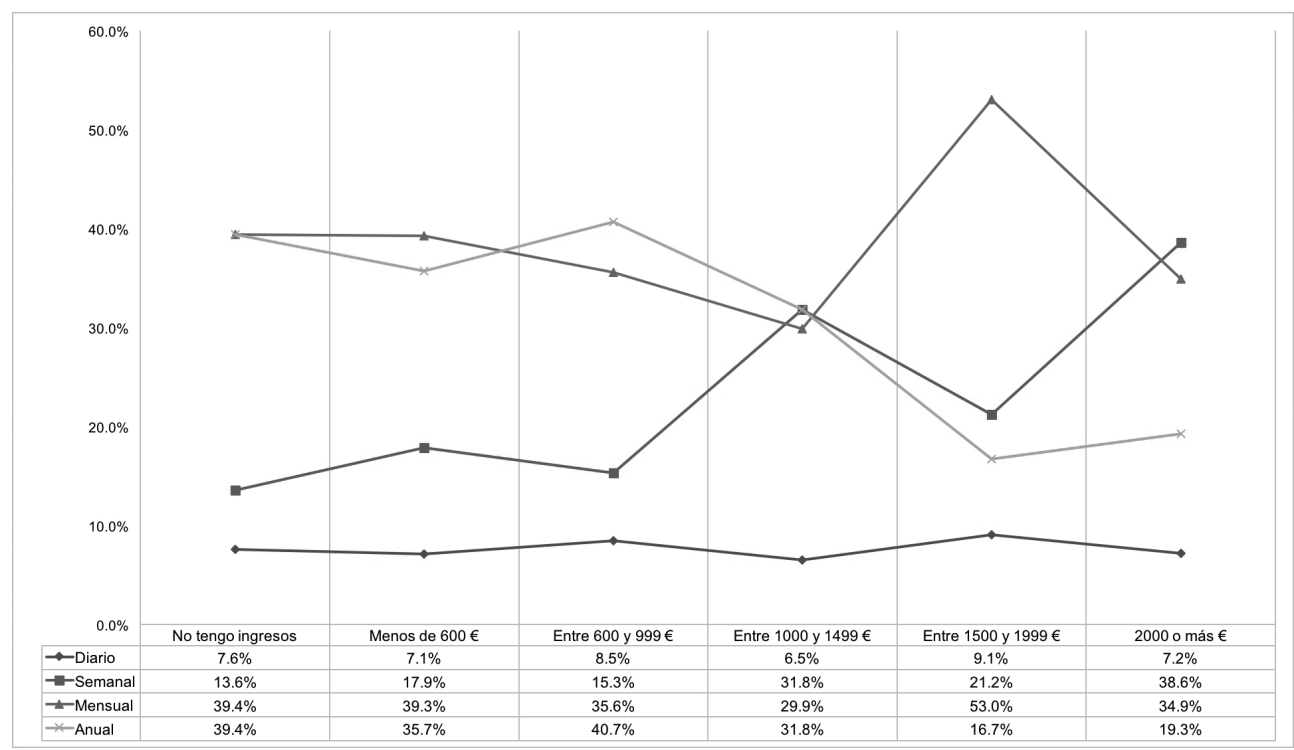

GRÁfICO 3.-Frecuencias de consumo por nivel de ingresos. Fuente: Datos del trabajo de campo

Como forma de complementar y reafirmar el argumento expresado anteriormente, tenemos los datos de las principales razones del no consumo de jamón ibérico. Resalta como la más importante el precio elevado del producto con $53 \%$ de los consumidores potenciales, seguido por un no gusto hacia el producto con $15 \%$ (Tabla 6). Estos valores bien pueden reflejar que el jamón ibérico se ha convertido en un alimento realmente hedónico que no está al alcance de todos los bolsillos. Ahora bien, los consumidores habituales de jamón ibérico, de acuerdo a los argumentos de las entrevistas en profundidad, parecen estar al margen de tiempos de crisis:

en el jamón no se sintió la crisis, el jamón se continúa vendiendo. Es un producto que no te lo vas a permitir todos los días, pero sí lo compras para ocasiones especiales... (Agente Comercial, entrevista personal, 22 nov. 2015).

\begin{tabular}{|l|c|}
\hline \multicolumn{1}{|c|}{ Categorías } & PorCentaje \\
\hline Precio elevado & 52,5 \\
\hline No me gusta & 14,6 \\
\hline Nunca me ha interesado & 6,3 \\
\hline Desconozco el producto & 1,7 \\
\hline No consumo carne & 6,7 \\
\hline Falta de costumbre & 6,7 \\
\hline Otros & 11,7 \\
\hline
\end{tabular}

TABLA 6.-Razones de no consumir jamón ibérico ${ }^{36}$. Fuente: datos del trabajo de campo

\footnotetext{
${ }^{36}$ La muestra fue conformada por $n=236$ no consumidores. Los valores están expresados en \%.
} 
Pero es momento de volver a las razones para consumir jamón ibérico. La principal, el placer y el gusto de comer un alimento tan representativo de la dieta mediterránea es inherente a los hábitos de su consumo. Por tanto, hay que relacionar preferencias con prácticas alimentarias, más aún cuando algunos consumidores y no consumidores argumentaban durante las entrevistas que eran veganos pero que sí consumían jamón ibérico. Como se desprende de la Figura 4, de acuerdo con la forma de consumirlo, los momentos del día y con quién se suele degustar, claramente estamos ante una sociedad que centra el consumo de este alimento durante prácticas y rituales festivos caracterizados por una elevada sociabilidad. Así, cerca del 54\% de los encuestados lo suele consumir en familia, siendo el momento de mayor consumo la cena (38\%) y su forma de comerlo es mayoritariamente como tapa o aperitivo (38\%). Gran parte de los consumidores degustan el jamón en más de un momento o situación (282), con más de una forma de preparación (273) y con más de un grupo de personas que no tiene que responder solo al grupo familiar (258). Estos datos nos trasladan a la flexibilidad del producto para encajar en multitud de situaciones del hecho alimentario.

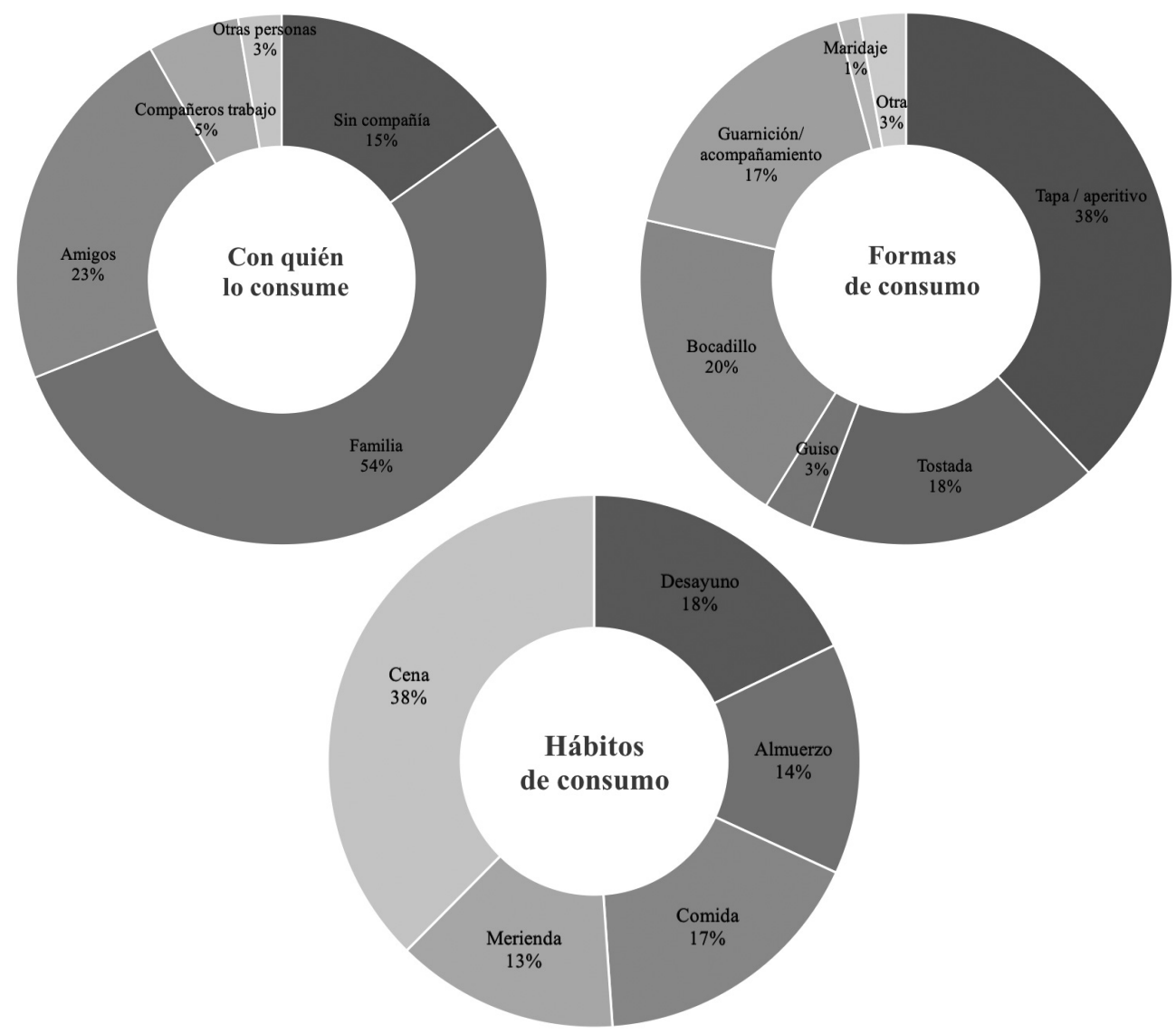

Figura 4 (a, b, c).-Hábitos de consumo de jamón ibérico. Fuente: datos del trabajo de campo 
El altísimo grado de sociabilidad/placer inherente al consumo de jamón ibérico viene reafirmado por los datos sobre los periodos prioritarios de su venta. Corresponden a dos fechas donde se concentran gran parte de festividades y celebraciones a lo largo de cada ciclo anual, en abril-mayo y diciembre. Lo afirmaba así uno de nuestros informantes: "la época de mayor venta es en abril por las fiestas que se celebran (bautizos y comuniones). Pero más en diciembre con la Navidad..." (Industrial de Valle de los Pedroches, entrevista personal, 27 oct. 2015).

Resulta interesante comparar las respuestas obtenidas en nuestro trabajo con datos de otras investigaciones sobre las percepciones alimentarias, concretamente sobre las preferencias para elegir unos u otros alimentos. Dos trabajos al respecto, uno sobre consumidores europeos y otro sobre los españoles serán nuestros referentes. El Pan European Survey of Consumer Attitudes to Food, Nutrition and Health de 2004 (citado en Contreras y Gracia 2008: 157), señala que, en el conjunto de la población europea, los criterios que declaraban los consumidores a la hora de elegir alimentos serían, en orden decreciente, los siguientes: "Calidad frescor", $74 \%$; "precio", $43 \%$; "gusto", $38 \%$; "comer sano", $32 \%$; y "lo que gusta a mi familia", $29 \%$. Para Contreras y Gracia (2008) en su trabajo denominado Preferencias y consumos alimentarios, la población española estaría más preocupada por la salud que el conjunto de la población europea (52,8\% frente al $32 \%$ ) y mucho menos preocupada por el precio (13,7 \% frente al $43 \%$ ). Para un mayoritario 52,8 \% su principal criterio de elección alimentaria fue la salud, respuesta que indica una constante, una tendencia dominante hoy en nuestra sociedad si nos atenemos a los resultados obtenidos en el caso del consumo de jamón ibérico (Tabla 4), tercer y muy poderoso criterio ante la elección de este alimento.

En el mismo sentido, obtener placer mediante la alimentación sigue siendo una finalidad importante para el ser humano ante el hecho alimentario. En el caso europeo ascendía a un $32 \%$ la relevancia de dicho criterio. Como queda demostrado en el caso de la elección y consumo de jamón ibérico en nuestro país, donde el peso del placer asciende a porcentajes mucho más elevados, está relacionado con quién se comparte (placer compartido) y con el uso de los tiempos, tiempos para disfrutar. De esta forma los momentos de no trabajo o excepcionales por alguna circunstancia, son los afines a la actividad de degustar placenteramente este alimento. Bautizos, comuniones, bodas y fiestas destacadas, fundamentalmente Navidad, son los momentos no cotidianos en el caso de mayor grado de consumo de jamón ibérico; y en cierto modo la no cotidianidad deviene del grado de placer obtenido mediante el consumo de alimentos como el jamón ibérico. Se busca disfrutar, comer aquello que más gusta, o lo que es lo mismo: que mayor placer proporciona, prescindiendo incluso de consideraciones de tipo nutricional y/o económicas.

En el consumo de jamón se sustancia el placer, la comodidad y la salud. En el acto de consumir este alimento no existe un tiempo prolongado de preparación, no interviene actividad de transformación donde la materia pasa de cruda a cocida, asada o frita (de naturaleza a cultura), por lo que estamos verdaderamente ante la comodidad como componente intrínseco del placer, pues necesita solamente ser cortado o, en su caso, extraerlo del envase si lo hemos adquirido cortado. Puede argüirse que cortar jamón no representa un trabajo fácil. Sin embargo, la acción del cortado de jamón es un valor añadido pues cortar canónicamente el jamón es una actividad 
especializada que pocas personas realizan. Quien lo lleva a cabo, añade al placer de consumirlo, el prestigio de cortarlo adecuadamente, pues no cualquiera puede llevarlo a cabo como nos comentaba uno de nuestros informantes:

yo tengo mis jamones, son de autoconsumo y un día vino una gente del norte y les vendí una pieza. A los pocos días me llaman y me dicen que el jamón está malo, que tiene mucha grasa... ¡Claro! si no conoces el producto y no lo sabes cortar, te va a parecer el peor producto... (Ganadero de Extremadura, entrevista personal, 2 jul. 2015).

Lo anterior nos confirma lo dinámico y cambiante de las percepciones. En este caso estamos ante la tendencia a ampliar el grado de placer asociado al consumo de jamón ibérico incluso más allá del acto de comerlo. La práctica del corte de jamón está incluida dentro de las acciones satisfactorias y hedónicas. Al contrario de representar una carga, es un valor añadido, simboliza prestigio derivado del saber hacer experto. Todo ello puede ser confirmado atendiendo a que el formato de compra del jamón en un 50,3\% de ocasiones es adquiriendo la pieza entera. Los consumidores que se guían por la practicidad, un 49,2\% elige el producto loncheado y solo un $5 \%$ lo prefiere deshuesado.

\section{CONCLUSIONES}

Si la gastronomía es una de las principales fuentes de placer del ser humano, el jamón ibérico, al menos en nuestro país, sería un producto muy relevante en la paleta de alimentos hedónicos. A este estereotipo contribuyen sus cualidades organolépticas y la capacidad de proporcionar infinidad de sensaciones. Sin embargo, en España, tal como demuestran nuestros datos, no come jamón ibérico toda la población, icono alimentario muy extendido dentro y fuera del país. Hemos demostrado que el $31 \%$ de la población no come ningún tipo de jamón en ninguna ocasión del año.

Pero nuestro trabajo nos ofrece datos cargados de significativos matices, datos que nos remiten a las actuales prácticas y percepciones sobre el consumo de jamón ibérico. En este sentido es muy revelador la periodicidad o frecuencia de consumo de jamón ibérico entre los españoles. Casi un $7 \%$ (43 de 582 personas) de consumidores lo come a diario y semanalmente en torno a una cuarta parte (183 de 582). Pero además de esta lectura meramente cuantitativa es necesario cualificar dicha realidad, añadiendo matices como los que hemos tratado aquí, fundamentalmente el altísimo nivel de sociabilidad/placer inherente al consumo de jamón ibérico. Este extremo se confirma con los datos aportados (momentos, formas de consumo, fechas prioritarias de venta y consumo...), lo que nos sitúa ante prácticas correspondientes a sociedades mediterráneas porcófilas. Prácticas de un sistema alimentario que más allá de estar determinadas por cuestiones monetarias, puesto que el jamón ibérico de bellota es caro para la mayor parte de las economías, se supeditan a momentos especiales para compartir con conocidos y familiares a través de la comensalidad.

Tal como se confirma mediante nuestros datos, estamos asistiendo a una elección alimentaria donde el hedonismo o el valor subjetivo del gusto y el placer por el alimento que se consume es la variable dominante sobre las demás del contexto investigado. Y a pesar de estar ante un tridente claramente abrumador donde, por orden 
de importancia tenemos al placer, la calidad y la salud como los tres primeros motivos a tener en cuenta por el consumidor para decantarse por consumir este alimento, sin duda el placer es la variable que domina. Este placer en el caso del jamón ibérico, tal como señalaron los informantes consumidores, es sinónimo de "delicioso", "buenísimo", "exquisito", "me encanta", "me gusta", "riquísimo", "sabor", "Sabroso", "orgasmo", "delicia", "alegría", "manjar"; apelativos que definen producto y sensaciones que van mucho más allá del momento de la degustación, del acto de comer, y que conlleva un posicionamiento, una actitud para seleccionar, elegir, decidir y disfrutar sobre el jamón ibérico tanto antes de su ingesta, como durante esta.

Por otro lado, nuestro análisis nos permite comprobar otra de nuestras hipótesis de partida, de modo que la percepción de salud (que en principio parecía que era un valor periférico, secundario) está íntimamente relacionada y forma parte del elevadísimo grado hedónico asociado al consumo de jamón ibérico. El placer gastronómico y la búsqueda de lo saludable tienen un papel sustancial en las preferencias alimentarias de nuestras sociedades occidentales y nuestro caso es paradigmático como hemos demostrado. En el caso del consumo del jamón ibérico esto es un hecho a pesar de que hay una tendencia generalizada a limitar el placer en la comida, pensando que lo saludable es comer menos o incluso anteponer productos que consideramos menos placenteros que otros y también menos perjudiciales. Esta tendencia está íntimamente relacionada con una aspiración de controlar el cuerpo a través de la dieta y la actividad física.

Este alimento, el jamón ibérico, finalmente y tal como hemos visto para el caso de la población española, es estructurante en los rituales festivos, cuando el comer y el beber festivos generan integración social. Si la comida más apreciada, la festiva, mueve a la conjunción grupal y la propia conjunción se sella con singulares comidas, ritualmente canónicas, aquí el jamón ibérico representa todo lo afirmado. Lo cual, además, imbrica este trabajo con la extensa construcción teórica y etnográfica sobre comida y fiestas, la comida e ideologías en torno al cuerpo y la salud. Son campos de análisis rigurosamente contemporáneos, nichos preferentes de reflexión que hablan de la comida como signo y como símbolo social para comprender algo mejor las dinámicas actuales.

\section{BIBLIOGRAFÍA CITADA}

Acosta, Rufino, Antonio L. Díaz y Santiago Amaya. 2001. Memoria de la tierra, campos de la memoria: los agroecosistemas tradicionales de Tentudia. V. 1, Dehesa y tierras calmas. Zafra: Centro de desarrollo comarcal de Tentudía.

Aguilar, Encarnación, Santiago Amaya Corchuelo e Ignacio López Moreno. 2016. "Alimentos con calidad. Nuevas estrategias rurales para nuevos consumidores". Arxiu d'Etnografia de Catalunya 16: 137-152.

Aguilar Piña, Paris. 2014. "Cultura y alimentación. Aspectos fundamentales para una visión comprensiva de la alimentación humana”. Anales de Antropología 48(1): 11-31.

Amaya-Corchuelo, Santiago. 2015. "Agricultura familiar en territorios de dehesa". Revista de La Facultad de Agronomía 114: 101-109.

Amaya-Corchuelo, Santiago y Encarnación Aguilar. 2012. "La construcción de la calidad alimentaria: tradición, innovación y poder en las DOP del jamón ibérico en España". Revista de Economia Agrícola 59(2): 39-52.

Amaya-Corchuelo, Santiago, José M. Froehlich, Encarnación Aguilar y Mario Fernández Zarza. 2016. "Uso de tradiciones culturales alimentarias para la promoción de productos con marcas de cali- 
dad certificada", en Manuel Luís Tibério, Ana Alexandra Marta Costa, Xerardo Pereiro, Ana Barros y Sônia Menezes (eds.), III Seminário "Alimentos e Manifestações Culturais Tradicionais" eo II Simpósio Internacional "Alimentação e Cultura: Tradição e Inovação na Produção e Consumo de Alimentos: 674-683. Vila Real: Universidade de Trás os Montes e Alto Douro.

Ascher, François. 2005. Le mangeur hypermoderne. Une figure de l'individu éclectique. París: Odile Jacob.

ASICI [Asociación Interprofesional del Cerdo Ibérico]. 2009. Plan Estratégico para el Sector del Porcino Ibérico. Zafra: Ministerio de Medio Ambiente y Medio Rural y Marino/Asociación Interprofesional del Cerdo Ibérico.

Bauman, Zygmunt. 2010. Mundo consumo: ética del individuo en la aldea global. Barcelona: Paidós.

Blogjamoniberico. 2012. "El nombre de pila del jamón ibérico se sabe galo". Blog del Jamón Ibérico 29 feb. Disponible en: < https://blogjamoniberico.wordpress.com/2012/02/29/el-nombre-de-piladel-jamon-iberico-se-sabe-galo/>. Fecha de acceso: 20 dic. 2016.

Bourdieu, Pierre. 1998. La distinción. Criterios y bases sociales del gusto. Madrid: Taurus.

Brillat Savarin, Jean A. 1854. The Physiology of Taste: or Meditations on Transcendental Gastronomy. Filadelfia: Lindsay y Blakiston.

Campillo, José E. 2007. "La dieta de la dehesa: la alimentación saludable en Extremadura", en Faustino Hermoso (ed.), VIII Congreso de Estudios Extremeños: Libro de actas: 32-35. Badajoz: Diputación de Badajoz.

Campos Palacín, Pablo. 1984. Economía y energía en la dehesa extremeña. Madrid: Instituto de Estudios Agrarios, Pesqueros y Alimentarios.

Carpenter, Kenneth J. 2003. "A short history of nutritional science: part 2 (1885-1912)". The Journal of Nutrition 133(4): 975-984.

Catani, Maurizio, Santiago Amaya y Antonio L. Díaz. 2001. Comer en Tentudía: aproximación etnográfica a la comida ya los hábitos de vida de las gentes de la comarca de Tentudía en los últimos setenta años. Zafra: Centro de Desarrollo Comarcal de Tentudía.

Conner, Mark T. y David A. Booth. 1992. "Combined measurement of food taste and consumer preference in the individual: reliability, precision and stability data". Journal of Food Quality 15(1): 1-17.

Contreras, Jesús. 2002. "Los aspectos culturales en el consumo de carne", en Mabel Arnáiz (coord.), Somos lo que comemos: Estudios de alimentación y cultura en España: 221-248. Barcelona: Ariel.

Contreras, Jesús y Mabel Gracia. 2008. "Preferencias y consumos alimentarios: entre el placer, la conveniencia y la salud", en Cecilia Méndez y Cristóbal Gómez (coords), Alimentación, consumo y salud: 155-191. Barcelona: Fundación La Caixa.

De Garine, Igor. 1998. "Antropología de la alimentación: entre naturaleza y cultura", en Alimentación y cultura. Actas del congreso internacional Museo Nacional de Antropología, 22-24 abril, Madrid, España: 13-34. Huesca: La Val de Onsera.

De Leeuw, Edith D. 2005. "To Mix or Not to Mix Data Collection Modes in Surveys". Journal of Official Statistics 21(2): 233-255.

Díaz, Cecilia y Cristóbal Gómez. 2005. “Consumo, seguridad alimentaria y salud. Una perspectiva de analisis desde las Ciencias Sociales". Revista Internacional de Sociología 63(40): 9-19. doi: <https://doi.org/10.3989/ris.2005.i40.187>.

Diez, Rosa W. 1997. "Práticas e comportamento alimentar no meio urbano: um estudo no centro da cidade de Säo Paulo". Cadernos Saúde Pública 13(3): 455-467.

Dillman, Don A., Jolene D. Smyth y Leah M. Christian. 2014. Internet, phone, mail, and mixed mode surveys: the tailored design method. Nueva Jersey: Hoboken.

Douglas, Mary y Baron C. Isherwood. 1979. El mundo de los bienes. Hacia una antropología del consumo. México D. F.: Consejo Nacional para la Cultura y las Artes.

Eggan, Fred y M. Pijcan. 1943. "Some problems in the study of food and nutrition". América Indigena 3: 9-22.

Espeitx Bernat, Elena. 1996. "Los "nuevos consumidores” o las nuevas relaciones entre campo y ciudad a través de los "productos de la tierra". Agricultura y Sociedad 80-81: 83-115.

Espeitx Bernat, Elena. 2005. "La alimentación como instrumento: restricciones alimentarias severas, consumos desmesurados y "dietas adelgazantes". Zainak. Cuadernos de Antropología Etnografía 27: 123-140. 
Fischler, Claude. 1995. El (b)omnívoro. El gusto, la cocina y el cuerpo. Barcelona: Anagrama.

García, Rolando. 2007. Sistemas complejos. Conceptos, método y fundamentación epistemológica de la investigación interdisciplinaria. Barcelona: Gedisa.

Gracia Arnaiz, Mabel. 2010. "Alimentación y cultura en España: una aproximación desde la antropología social". Physis Revista de Saúde Coletiva 20(2): 357-386.

Guerrero, Luis, Anna Claret, Wim Verbeke, Geraldine Enderli, Sylwia Zakowska Biemans, Filiep Vanhonacker, Sylvie Issanchou, Marta Sajdakowska, Britt Signe Granli et al. 2010. "Perception of traditional food products in six European regions using free word association". Food Quality and Preference 21(2): 225-233.

Goody, Jack. 1995. Cocina, cuisine y clase: estudio de sociología comparada. Barcelona: Editorial Gedisa.

Guthe, Carl E. 1945. Manual for the Study of Food Habits. Report of the Committee of food habits. Bulletin of the National Research Council, 111. Washington, D.C: National Research Council.

Harris, Marvin. 1985. Bueno para comer. Enigmas de alimentacidn y cultura. Madrid: Alianza.

INE [Instituto Nacional de Estadística]. 2015. "Encuesta sobre Equipamiento y Uso de Tecnologías de Información y Comunicación en los Hogares". Disponible en: <http://www.ine.es/prensa/ np933.pdf>. Fecha de acceso: 11 may. 2016.

Jelliffe, Derrick B. 1967. "Parallel food classifications in developing and industrialized countries". The American Journal of Clinical Nutrition 20(3): 279-281.

Jerome, Norge W. 1979. "Changing nutritional styles within the context of the modern family". Family Health Care 1: 194-203.

Jurado, Ángela, Carmen García, María L. Timón y Ana I. Carrapiso. 2007. "Effect of ripening time and rearing system on amino acid related flavour compounds of Iberian ham". Meat Science 75(4): 585-594.

Lambert, Jean-Louis. 2004. "Modes de vie et comportements alimentaires dans notre société actuelle". Colloque Des aliments et des hommes. Entre science et idéologie, définir ses propres repères. París: Institut Français de Nutrition.

Leach, Edmund. 1989. "Anthropological aspects of language: Animal categories and verbal abuse". Anthrozoös 2(3): 151-165.

Lévi Strauss, Claude. 2004 [1965]: "Le triangle culinaire». Food E History 2: 9-19. doi: <https://doi.org/ 10.1484/J.FOOD.2.300271>.

Leyva, Doris A. y Arturo Pérez. 2015. "Pérdida de las raíces culinarias por la transformación en la cultura alimentaria”. Revista Mexicanan de Ciencias Agricolas 6(4): 867-881.

López, Julián, Lorenzo Mariano y Francisco X. Medina. 2017. "Usos y significados contemporáneos de la comida desde la antropología de la alimentación en América Latina y España". Revista de Dialectología y Tradiciones Populares 71(2): 327-370.

Lozano, Carmen y Encarnación Aguilar. 2010. "Natural, tradicional y de la tierra: la promoción de la calidad agroalimentaria en los nuevos espacios rurales andaluces", en Marta Soler y Carmen Guerrero (coords.), Patrimonio cultural en la nueva ruralidad andaluza: 126-139. Sevilla: Universidad de Sevilla.

Luhmann, Niklas. 1998. Sistemas sociales: lineamientos para una teoría general. Barcelona: Anthropos Editorial.

Mauss, Marcel. 1994. Le fait social total. París: Presses universitaires de France, PUF.

MAPAMA [Ministerio de Agricultura y Pesca, Alimentación y Medioambiente]. 2016. "Caracterización del sector porcino español 2015". Disponible en: <http://www.mapama.gob.es/es/ganaderia/temas/produccion-y-mercados-ganaderos/caracterizaciondelsectorporcinoespanolano2015_tcm30104637.pdf>. Fecha de acceso: 24 may. 2018.

Marcos, Javier. 1989. "La cerdofilia extremeña. Una visión desde la Antropología". Folk Lore Andaluz 4: 129-137.

Martínez, Herminia. 2015. "Informe 2015 del sector de cerdo ibérico". Alimarket 23 oct. Disponible en: <https://www.alimarket.es/informe/194483/informe 2015 del sector de cerdo iberico>. Fecha de acceso: 16 oct. 2016.

Maslow, Abraham H. 1962. Toward a psychology of being. Princeton (NJ): Van Nostrand.

OCN FENACO. 2014. "Rubén Bravo, Naturópata experto en Nutrición del Instituto Médico Europeo de la Obesidad, ha elaborado una dieta basada en el jamón ibérico y el vino tinto". Disponible 
en: <http://naturopatiadigital2.blogspot.com.es/2014/04/ruben bravo naturopata experto en.html>. Fecha de acceso: 1 dic. 2016.

Pérez Palacios, Trinidad, Jorge Ruiz y Teresa Antequera. 2008. “Perfil de ácidos grasos de la grasa subcutánea e intramuscular de credos ibéricos cebados en montanera y con pienso alto oleico". Eurocarne 18(163): 159-170.

Pollan, Michael. 2014. Cocinar: una historia natural de la transformación. Barcelona: Debate.

Rappaport, Roy A. 1987. Cerdos para los antepasados: ritual en la ecología de un pueblo en Nueva Guinea. Madrid: Siglo XXI.

Rozin, Paul y April Fallon. 1986. "The acquisition of likes and dislikes for foods", en National Research Council (US) Food and Nutrition Board (ed.), What Is America Eating?: Proceedings of a Symposium: 58-71. Washington D. C.: National Academies Press.

Silva, Antonio, Raquel Reina y Jesús Ventanas. 2010. "La certificación de la calidad y de la alimentación en jamones y paletas de cerdo ibérico", en José Miguel Coleto Martínez, Enrique de Muslera Pardo, Raquel González Blanco y Francisco Pulido García (coord.), La agricultura y la ganadería extremeñas: informe 2009: 79-90. Badajoz: Caja de Ahorros de Badajoz.

Solomon, Michael, Gary J. Bamossy, Søren Askergaard, S. y Margaret K. Hogg. 2006. Consumer behavior: a European perspective. Edimburgo: Pearson Education Limited.

Fecha de recepción: 22 de mayo de 2017

Fecha de aceptación: 14 de febrero de 2018 